Pittsburgh University School of Law

Scholarship@PITT LAW

Articles

Faculty Publications

2014

\title{
At the Tipping Point: Race and Gender Discrimination in a Common Economic Transaction
}

Lu-in Wang

University of Pittsburgh School of Law, lu-inwang@pitt.edu

Follow this and additional works at: https://scholarship.law.pitt.edu/fac_articles

Part of the Benefits and Compensation Commons, Business Administration, Management, and Operations Commons, Business Law, Public Responsibility, and Ethics Commons, Civil Rights and

Discrimination Commons, Hospitality Administration and Management Commons, Labor and

Employment Law Commons, Law and Gender Commons, Law and Race Commons, and the Law and

Society Commons

\section{Recommended Citation}

Lu-in Wang, At the Tipping Point: Race and Gender Discrimination in a Common Economic Transaction, 21 Virginia Journal of Social Policy and the Law 101 (2014).

Available at: https://scholarship.law.pitt.edu/fac_articles/163

This Article is brought to you for free and open access by the Faculty Publications at Scholarship@PITT LAW. It has been accepted for inclusion in Articles by an authorized administrator of Scholarship@PITT LAW. For more information, please contact leers@pitt.edu, shephard@pitt.edu. 


\section{AT THE TIPPING POINT: RACE AND GENDER DISCRIMINATION IN A COMMON ECONOMIC TRANSACTION}

\section{Lu-in Wang*}

\section{ABSTRACT}

This Article examines the ubiquitous, multibillion-dollar practice of tipping as a vehicle for race and gender discrimination and as a case study of the role that organizations play in producing and promoting unequal treatment. The unique structure of tipped service encounters provides opportunities and incentives for both customers and servers to discriminate against one another. However, neither customers nor servers are likely to find legal redress for the kinds of discrimination that are most likely to occur in tipped service transactions because many of the same features of the transaction that promote discrimination also stand in the way of legal accountability for the discrimination that results.

Moreover, while tipped service transactions directly involve just the customer and server, they take place within an organizational framework that is created by a third party-the firm that sells to the customer and employs the server. That framework facilitates discriminatory bias in the decisions of customers and servers and encourages the firm to make decisions that reinforce the discriminatory dynamics of the service encounter. Further, the "triangular" structure of the relationship among firm, customer, and server obscures the firm's role in producing discriminatory outcomes and protects the firm against liability. Close examination of discrimination in tipped service encounters reveals the importance of supporting a newer, structural approach to antidiscrimination law that looks beyond individual decision making.

\section{CONTENTS}

Abstract

I. Introduction

II. The Point of Tipping: "Why Pay Extra"

III. "Transaction Within a Transaction": The

"Microcosmic" Relationship Between Tipper and Tippee

\footnotetext{
* Professor of Law, University of New Mexico School of Law. Many thanks to colleagues and friends who read and provided helpful comments on earlier drafts, especially Debbie Brake, Martha Chamallas, Mary Crossley, and Dave Herring, and to Stephanie Wildman for inviting me to present a part of this work at a Santa Clara University Gender \& Law Conference. I also thank colleagues and students at my former academic home, the University of Pittsburgh School of Law, for generous support, including a Dean's Scholarship; excellent research assistance from Marc Silverman, Linda Tashbook, Michele Kristakis, Brandon Gatto, and Carly LaBuff; and the technological wizardry of the Document Technology Center.
} 
IV. Situational Discrimination and Self-Fulfilling Stereotypes

in Tipped Transactions

A. The Normatively Ambiguous Situation of Tipping

B. "Service with a Smirk": Normative Ambiguity in Restaurant Service

C. "A Mutually Reinforcing, Unhappy Equilibrium"

V. Implications of the "Triangular Relationship": Towards a

Structural Approach to Reform.

VI. Conclusion

\section{INTRODUCTION}

This Article examines the practice of tipping ${ }^{\prime}$ as a vehicle for race and gender discrimination by both customers and servers. Seemingly trivial and often overlooked, tipping is, in fact, highly significant as an economic matter. ${ }^{2}$ A recent estimate put annual tipping in the United States restaurant industry alone at $\$ 46.6$ billion, while noting that this is just one industry among several in which tipping is common. ${ }^{3}$ Indeed, given how widespread the practice has become in the United States, most of us engage in tipped transactions on a regular, if not daily, basis as customers. For the millions of us who also work for tips, ${ }^{4}$ this

'For the purposes of this Article, "tipping" is the voluntary payment by the recipient of a service to the person who provides the service. Voluntary payments of this kind are customary for a wide range of services in the United States. This Article focuses on the most common and economically significant category, what economist Ofer H. Azar calls "reward-tipping." Reward tips are given after a service is provided, the most common example being tips given to restaurant servers. Other service workers-such as cab drivers and bellhopsare also tipped in this fashion customarily. See Ofer H. Azar, Why Pay Extra? Tipping and the Importance of Social Norms and Feelings in Economic Theory, 36 J. SOCIO-ECON. 250, 255 (2007) [hereinafter Azar, Why Pay Extra?] (describing six categories into which the practice of tipping can fall).

${ }^{2}$ Ofer H. Azar, The Social Norm of Tipping: A Review, 37 J. APPLIED Soc. PsyCHOL. 380, 380-81 (2007) [hereinafter Azar, The Social Norm of Tipping].

${ }^{3}$ Ofer H. Azar, Business Strategy and the Social Norm of Tipping, 32 J. ECON. Psychol. 515, 516 (2011) [hereinafter Azar, Business Strategy].

${ }^{4}$ Focusing on just waiters, waitresses, and bartenders, a 2009 report estimated the number of tipped workers in restaurants at nearly 2.9 million. RAJESH D. Nayak \& PaUl K. Sonn, National EMPloyment law Project, Restoring THE MINIMUM WAGE FOR AMERICA'S TIPPED WORKERS 3 and 20 n.3 (2009). See also SYlvia A. AllegretTo \& KaI FILION, ECONOMIC POLICY INSTITUTE, Waiting for Change: The $\$ 2.13$ Federal Subminimum Wage 6 (Feb. 23, 2011) (estimating based on 2008 and 2009 data that "there are approximately 3.3 million tipped workers in the United States"). 
"notoriously erratic" 5 source of compensation can mean "the difference between a subsistence and a living wage."

For many, women and people of color in particular, this ubiquitous practice is also a source for unequal economic outcomes on both sides of the transaction, because their unique structure makes tipped service encounters particularly susceptible to the influence of race and gender stereotypes and bias. Women as tippers are subject to derogatory stereotypes that make them vulnerable to discriminatory service, while women as servers both are highly dependent on tip income ${ }^{7}$ and work in an environment where gender stereotypes are especially pervasive and strong. ${ }^{8}$ People of color also experience discrimination from both directions and in multiple ways: They are less likely to hold tipped positions; ${ }^{9}$ they receive substantially lower tips and are more likely to be "stiffed" (not tipped at all) than white workers when they do hold such positions, ${ }^{10}$ and they often receive inferior and humiliating treatment as customers because of negative stereotypes about their tipping practices. ${ }^{11}$

Even as the structure of tipped transactions provides incentives and opportunities for servers and customers to discriminate against one

\footnotetext{
${ }^{5}$ NAYAK \& SONN, supra note 4 , at 7.

${ }^{6}$ Fred Davis, The Cabdriver and His Fare: Facets of a Fleeting Relationship, 65 AM. J. Soc. 158, 161 (1959). The Fair Labor Standards Act provides a "tip credit" towards the minimum wage obligation for employers of tipped workers under which the employer may be required to pay a cash wage of as low as $\$ 2.13$ per hour. See 29 U.S.C. $\$ 203(\mathrm{~m})$ (2006); WAGE AND HOUR DIVISION, U.S. DEPT. OF LABOR, FACT SHEET \#15: TIPPED EMPLOYEES UNDER THE FAIR LABOR STANDARDS ACT (FLSA) (rev. Mar. 2011), available a thttp://www.dol.g ov/whd/regs/compliance/whdfs15.pdf. See generally NAYAK \& SONN, supra note 4; AlLEGRETTO \& FILION, supra note 4. Accordingly, millions of tipped workers derive the majority of their income from tips. For example, waiters and waitresses derive about $58 \%$ of their income from tips and bartenders about 52\%. See PaYSCAle, How Your Tips Impact Incomes: PayScale's 2012-2013 Tipping Study, http://www.payscale.com/tipping-chart-2012 (last visited on Feb. 18, 2013).

${ }^{7}$ In the restaurant industry, for example, over seventy percent of wait staff positions are held by women. See WOMEN's BUREAU, U.S. DEPT. OF LABOR, 20 LEADING OCCUPATIONS OF EMPLOYED WOMEN: 2010 ANNUAL AVERAGES, available at $\mathrm{http}: / \mathrm{www}$.dol.gov/wb/factsheets/20lead2010.htm.

${ }^{8}$ See generally ReStaurant OPPORTUNiTIES CENTERS UNITED ET AL., TIPPED OVER THE EDGE: GENDER INEQUITY IN THE RESTAURANT INDUSTRY (Feb. 13, 2012), available at http://rocunited.org/files/2012/02/ROC_GenderInequity_F11.pdf.

${ }^{9}$ See AllegretTo \& Filion, supra note 4, at 6 ("Tipped workers, especially waiters, are less likely to be black, a demographic that is under-represented in this line of work compared with its representation in the overall workforce.").

${ }^{10}$ See infra notes 21-24 and Part IV.A.

${ }^{11}$ See infra Part IV.B.
} 
another, that structure also stands in the way of legal accountability for the discrimination that results. As immediate parties to the encounter, the customer and server most directly feel and inflict discrimination in service and compensation, but that discrimination generally takes a form that is not legally remediable under existing law. ${ }^{12}$ Moreover, the customer-server interaction is structured and largely controlled by a powerful but nearly invisible third party-the firm that provides the service and employs the tipped server. The firm sets the conditions of the service encounter and chooses to rely on customers' tips to compensate its workers. By choosing to compensate its workers through tips, the firm essentially delegates to customers the task of monitoring and rewarding service quality ${ }^{13}$ thereby creating incentives and opportunities for customers and servers to discriminate. Yet, the "triangular"14 structure of the relationship among firm, customer, and server both obscures the firm's role in producing discriminatory outcomes and protects the firm against liability to either of the other parties.

Tipping as a general practice is both widely accepted and controversial. It has provoked vigorous debate and even legal prohibition since it was first introduced in the United States in the late nineteenth century, ${ }^{15}$ and disagreements over its desirability continue to this day. ${ }^{16}$ Tipping also reveals aspects of human behavior that are generally not open to view, as empirical studies by economists, sociologists, and social psychologists have found. ${ }^{17}$ In particular, empirical studies have uncovered group-related differences in behavior and outcomes on both sides of the tipping transaction, providing an uncommon opportunity to view objectively the effects of social stereotypes and bias on economic behavior. $^{18}$

${ }^{12}$ See discussion infra Part V.

${ }^{13}$ See discussion infra Part II.

${ }^{14}$ Lorraine Bayard de Volo, Service and Surveillance: Infrapolitics at Work Among Casino Cocktail Waitresses, 10 SoC. POL. 346, 362 (2003).

${ }^{15}$ See generally KERRY SEgraVE, TIPPING: AN AMERICAN SOCIAL History OF GratuITIES (1998); Ofer H. Azar, The History of Tipping-From SixteenthCentury England to United States in the 1910s, 33 J. Socio-ECON. 745 (2004) [hereinafter Azar, The History of Tipping].

${ }^{16}$ See, e.g., Brian Palmer, Tipping Is an Abomination: Here's How to Get Rid of It, SLATE (July 9, 2013), http://www.slate.com/articles/business/moneybox/2013 /07/abolish_tipping_it_s_bad_for_servers_customers_and_restaurants.html;

Room for Debate: To Tip or Not To Tip, N.Y. TIMES (June 23, 2013), http://www.nytimes.com/roomfordebate/2013/06/23/to-tip-or-not-to-tip.

17 See Azar, Why Pay Extra?, supra note 1, at 251.

${ }^{18}$ Economist Ofer $H$. Azar has noted that "[t]he advantage of tipping as a research topic is that it is a relatively simple context and therefore it allows for interventions that may be difficult to do in complex settings such as the workplace." Azar, Business Strategy, supra note 3, at 517. 
First, tipping studies have examined how bias can influence both sides of an economic exchange- the "buyer" (customer) side and the "seller" (server) side - as well as how biases on both sides might interact with and reinforce one another. As Ian Ayres, Fredrick E. Vars, and Nasser Zakariya pointed out in their 2001 study of the tipping of taxicab drivers, civil rights laws protect buyers against discrimination by sellers, but not vice versa, and studies of economic discrimination likewise typically focus on seller-side discrimination. ${ }^{19}$ Their study and others suggest, however, that "consumer discretion in retail transactions"which provides the opportunity for discrimination by buyers- "may give rise to unexpected civil rights concerns." ${ }^{20}$

Studies of tipping also provide objective measures of differences in economic behavior and outcomes in real life, non-laboratory settings. As elaborated below, tipping behavior is extremely telling, because it is voluntary, discretionary, and spontaneous. Studies show that tipping transactions are affected by subtle, perhaps unconscious factors, such as race and gender bias. The studies also provide quantitative evidence of differential treatment and therefore of the material effect of such bias. ${ }^{21}$ Because the tipper is at least nominally free to choose whether to tip at all and controls the amount given, researchers can quantify the difference in treatment of servers by variables including social group membership. For example, the study of taxicab tipping in New Haven, Connecticut by Ayres et al. found that "passengers systematically tipped white drivers substantially more than nonwhite drivers": $61 \%$ more than black drivers and $64 \%$ more than other minority drivers. ${ }^{22}$ Passengers were also $80 \%$ and $131 \%$ more likely to "stiff" black and other minority drivers, respectively, than white drivers. ${ }^{23}$ Interestingly, black passengers discriminated just as white passengers did, tipping white drivers $67 \%$ more than black drivers and stiffing black drivers at a higher rate than white drivers. ${ }^{24} \mathrm{~A}$ more recent study by a leading expert on tipping

${ }^{19}$ See Ian Ayres et al., To Insure Prejudice: Racial Disparities in Taxicab Tipping, 114 YALE L.J. 1613, 1615 (2005) ("It has become increasingly common to test whether sellers in retail markets discriminate against buyers."). Ayres and his colleagues designed their study of tipping for cab rides as "one of the first efforts to test the other side of the market," explaining that the failure to test on the buyer side is "unjustified," given that "[t]ests of consumer-side race discrimination are just as feasible as seller-side testing." Id.

${ }^{20}$ Id. at 1663.

${ }^{21}$ See id. at 1616 (noting that taxicab tipping "is a dimension of consumer economic behavior that is both discretionary and potentially observable").

${ }^{22} \mathrm{Id}$. at 1627 . The researchers analyzed and rejected the possibility that factors other than driver race - including "individual-driver effects," "disparate driver quality," and "disparate customers"-accounted for the disparities observed. See id. at 164448 .

${ }^{23}$ Id. at 1627 .

${ }^{24}$ See id. at $1627,1629$. 
behavior, Michael Lynn, and his colleagues found that restaurant customers in Mississippi tipped black servers significantly less than white servers (17.5\% vs. $20.7 \%$ and $14.6 \%$ vs. $19.4 \%$, depending on the size of the dining party), and again that black customers as well as white discriminated in this way. ${ }^{25}$ Given that tips constitute a high proportion of many service workers' compensation, these variations can have "enormous income consequences when accumulated" over many transactions. ${ }^{26}$

Seller's or server's side differential treatment of customers based on race or other social group membership cannot as readily be quantified. Nevertheless, abundant evidence-from both research studies and servers' reports of their own and coworkers' behavior-shows that servers often hold stereotypes about particular groups' tipping practices, ${ }^{27}$ frequently paired with stereotypes about their behavior generally as customers, that can influence the level or type of service provided to members of stereotyped groups. ${ }^{28}$ In interviews and online

${ }^{25}$ Michael Lynn et al., Consumer Racial Discrimination in Tipping: $A$ Replication and Extension, 38 J. APPLIED SOC. PSYCHOL. 1045, 1051-55 (2008) (replicating and extending the study by Ayres et al., supra note 19) [hereinafter Lynn et al., Consumer Racial Discrimination in Tipping]; see also Michael Lynn et al., Does Seller Race Affect Consumer Behavior? Evidence for Racial Discrimination among Restaurant Patrons (Cornell Univ. Sch. of Hotel Admin. Ctr. for Hospitality Research, Working Paper Series No. 03-01-05) (earlier version of same study). Note that the study controlled for customers' ratings of service quality: Several other studies, while not focusing specifically on groupbased differences in tips received, also suggest the potential influence of social stereotypes and bias on tipping behavior. See discussion infra Part IV.A.

${ }^{26}$ Michael Lynn \& Tony Simons, Predictors of Male and Female Servers' Average Tip Earnings, 30 J. APPLIED SOC. PSYCHOL. 241 (2000). Ayres and his co-authors further note that the tax laws might "add insult to injury" to minority drivers and, presumably other minority group members who work for tips "by directly or indirectly attributing phantom tipping income to minority drivers"in other words, by taxing them based on the same imputed tax income even though their tips are lower than those of their white counterparts or by focusing on them for audit based upon a suspicion that they are underreporting tip income when, in fact, they are not. Ayres et al., supra note 19, at 1656-58.

${ }^{27}$ In fact, as will be discussed below, some of these assumptions about particular groups' tipping practices have been confirmed empirically. The reasons for these differences may implicate factors such as socioeconomic class and the complicated expectations and social dynamics surrounding tipping that themselves reflect the influence of stereotypes and bias. See discussion infra Part IV.C.

${ }^{28}$ Along these lines, Ayres and his co-authors suggest that it might be expectations about the poor tipping practices of African Americans, and not fear of crime as has often been suggested, that account for the well-publicized phenomenon of cab drivers' refusing to pick up minority passengers. Ayres et al., supra note 19 , at 1617 . For discussion of an audit study of racial 
discussions, restaurant servers comment frankly about "profiling" customers based on stereotypes related to tipping. ${ }^{29}$ Online postings, for example, have characterized African Americans as demanding customers who are "cheap" or refuse to tip altogether and women as finicky, entréesharing, calculator-using, low tippers, especially when they dine in groups. The elderly, religious, and rural also are expected to tip poorly. Servers admit that they try to avoid being assigned to tables occupied by members of groups that are stereotyped as bad tippers, and that they are less likely or motivated to provide them with good service. ${ }^{30}$ Acting on such stereotypes, some establishments have tried to ensure that their servers receive tips from members of these groups by adding a gratuity to the bills of customers they expect will be low or non-tippers, but not to the bills of other customers. ${ }^{31}$

Stereotypes impose costs on members of stigmatized groups when they are refused service, provided with inferior service, or humiliated by having service charges added to their checks. In addition, concern about expectations that they will tip poorly might lead some members of stereotyped groups to overcompensate. Regina Austin has written that she sometimes over-tips as a way of challenging stereotypes: "I sometimes give a waiter or cab driver a generous tip despite poor service in an effort to debunk the common complaint that blacks do not tip; I hope that the next black patron will reap the benefit of my generosity." 32 Professor Austin characterizes this practice as "sell[ing oneself] in order to be sold to." 33

discrimination in taxi service in Washington, D.C., see Peter Siegelman, Racial Discrimination in "Everyday" Commercial Transactions: What Do We Know, What Do We Need to Know, and How Can We Find Out?, in THE URBAN INST., A NATIONAL REPORT CARD ON DisCRIMINATION IN AMERICA: THE ROLE OF TESTING 69, 76-79 (Michael Fix \& Margery Austin Turner eds., 1998) (reporting that "blacks had to wait, on average, 27 percent longer for a cab to stop"; also criticizing the study design).

${ }^{29}$ See discussion forums at Tipping.org, Discussions, THE ORIGINAL TIPPING PAGE, http://www.tipping.org/discussions/ (last visited Oct 22, 2013); Danielle Dirks \& Stephen K. Rice, "Dining While Black": Tipping as Social Artifact, 45 CORNELl HOTEL \& RESTAURANT ADMIN. Q. 30, 33 (2004) [hereinafter Dirks \& Rice, Tipping as Social Artifact]; and discussion infra Part IV.B.

${ }^{30}$ See discussion infra Part IV.B.

${ }^{31}$ See Michael Lynn \& Clorice Thomas-Haysbert, Ethnic Differences in Tipping: Evidence, Explanations, and Implications, 33 J. APPLIED SOC. PSYCHOL. 1747, 1747 (2003) (describing 1999 incident at Thai Toni Restaurant in Miami Beach, Florida); see also BARBARA EHRENREICH, NICKEL AND DiMED: ON (NOT) GETTING BY IN AMERICA 19 (2001).

${ }^{32}$ Regina Austin, "A Nation of Thieves": Securing Black People's Right to Shop and to Sell in White America, 1994 UTAH L. REV. 147, 154.

${ }^{33}$ Id.; see also Jerry Large, Tipping as a Race Issue: Waiters and Diners, Mutually Wary, SEATTLE TIMES, June 11, 2006, http://seattletimes.com/html/ 
This Article examines tipped service transactions as an important source of economic discrimination that evades legal remedy, and thereby supports the need for a newer, structural approach to antidiscrimination law. ${ }^{34}$ To make its case, the Article illuminates specific ways in which tipped service encounters both allow for and promote discrimination. Part II outlines the reasons for the puzzling practice of tipping, explaining that it fulfills economic, psychological, and social functions for the tipper. Part III describes the structure and tensions of the tipped service encounter, which is far more complex than one might expect of what appears to be an isolated, arms-length transaction. Part IV then elaborates the ways in which these features of the encounter allow stereotypes and bias to "tip" 35 the transaction into race and gender discrimination by both customer and server, as well as the processes by which the expectations of parties on both sides of the exchange can produce a "mutually reinforcing, unhappy equilibrium" 36 of economic discrimination. Part V shows why existing legal approaches are ill-suited to address the kind of discrimination that tipping produces. The Article closes by adding to other scholars' calls for a structural approach to legal accountability, explaining why the triangular relationship among firm, server, and customer creates an organizational framework that encourages biased decision-making and behavior by all three parties.

\section{The POINT OF TIPPING: "Why PAY EXTRA"37}

While it may be well-established, tipping is something of an economic oddity that raises a basic question: ${ }^{38}$ Why do people do it?

jerrylarge/2003051233_jdl11.html ("I'm very conscious of my behavior and tipping in restaurants. I want to leave a good impression, partly due to my assumption that servers might have some bias against me. When waiters are especially nice, I sometimes overdo. It's dumb all around.").

${ }^{34}$ See generally, e.g., Tristin K. Green, A Structural Approach as Antidiscrimination Mandate: Locating Employer Wrong, 60 VAND. L. REV. 849, 857 (2007).

${ }^{35}$ The idea that "little things" can "tip" a situation across a threshold to rapid change, as well as the term "tipping point," has become popular with the publication of MALCOLM GladWELl, THE TIPPING POINT: How LitTLE THINGS CAN MAKe a Big Difference (2000). The term appears to have "entered the academic lexicon" much earlier than that, however, "when it was used by political scientist Morton Grodzins in 1957 in his sociological studies on racial segregation to describe the critical threshold at which the white population would leave an area where more and more black people were present." Since then, the use of the metaphor has "evolved and spread across many disciplines." Pojanath Bhatanacharoen, David Greatbatch \& Timothy Clark, The Tipping Point of the "Tipping Point" Metaphor: Agency and Process for Waves of Change, INST. OF HAZARD, RISK \& RESILIENCE 1, http://www.dur.ac.uk/resourc es/ihrr/tippingpoints/OLKCPaperforlHRR.pdf.

${ }^{36}$ Ayres et al., supra note 19, at 1651.

${ }^{37}$ Azar, Why Pay Extra?, supra note 1. 
That is, why pay extra for a service when one is not legally obligated to do so and the service has already been given? The practice seems irrational from a purely economic perspective, because we expect people to pay as little as possible for goods and services and not to give money to strangers when there is no requirement or direct benefit for doing so. ${ }^{39}$

In fact, tipping may not be entirely irrational, and its economic justification rests on the very triangular structure it imposes on the relationship among firm, customer, and server that, as we will see, both promotes discrimination and impedes legal accountability. That is, tipping provides a way to monitor and improve service quality by delegating to the customer the function of assessing and rewarding the service received. One might expect management to play the primary role in controlling the quality of service provided by its workers, incorporating its cost of doing so into the price it charges customers. For example, a firm might impose a flat service charge and itself determine whether employees meet its standards of performance. The expected arrangement will not be efficient, however, if the firm cannot easily monitor service (if, e.g., some aspects of service are intangible or customized) or the server does not have an incentive to provide good service (if, e.g., the server's compensation does not vary with service quality). ${ }^{40}$ In those situations, the customer is better positioned to assess service quality and provide incentives to the server. ${ }^{41}$

${ }^{38}$ See Michael Lynn \& Michael McCall, Gratitude and Gratuity: A MetaAnalysis of Research on the Service-Tipping Relationship, 29 J. Socio-ECON. 203, 204 (2000) (stating that tipping "represents a multibillion dollar exception to [the] general rule" of economic behavior) [hereinafter Lynn \& McCall, Gratitude and Gratuity].

${ }^{39}$ See Azar, Why Pay Extra?, supra note 1, at 250; Lynn \& McCall, Gratitude and Gratuity, supra note 38, at 204.

${ }^{40}$ Cf. Uri Ben-Zion \& Edi Karni, "Tip" Payments and the Quality of Service, in ESSAYS IN LABOR MARKET ANALYSIS 37 (Orley C. Ashenfelter \& Wallace E. Oates eds., 1977).

${ }^{41}$ Such an arrangement could take the form of a service contract between customer and server, but to develop such a contract for each transaction would entail high transaction costs for negotiation and enforcement. Azar, Why Pay Extra?, supra note 1, at 256-57. Accordingly, the leading economic explanation for the practice is that tipping developed as a more efficient substitute for a service contract: In place of costly negotiation, an implicit understanding allows the customer to adjust the reward for service after it has been provided, based on an assessment of its quality, thereby also giving the server incentive to exert effort to please the customer. See David HEMENWAY, Prices AND Choices: Microeconomic VignetTes 92 (2d ed. 1988); Azar, Why Pay Extra?, supra note 1, at 255-57; Ben-Zion \& Karni, supra note 40, at 43 . By establishing tipping as a social norm, moreover, society has also created an efficient enforcement mechanism. A third party need not be involved in enforcing the implicit contract (which would require that party to second guess the customer's 
Consistent with this theory, people do relate tipping to service quality. The most common explanation people give for why they tip is to reward good service ${ }^{42}$ Etiquette guides reinforce this connection by advising readers to tip according to the level of service received - not only to tip generously for excellent service, but also to adjust the tip downward for unsatisfactory service, or to not tip at all if service "is bad enough." ${ }^{33}$ Otherwise, Emily Post's Etiquette warns, "there is no incentive to make any extra effort at all." ${ }^{\text {44 }}$ Empirical evidence shows that customers' actual tips do reflect adjustments based on their evaluations of the service they have received. ${ }^{45}$

Even so, service quality is not a strong explanation for tipping, nor is it the only factor that affects tipping behavior. Studies that have found a positive relationship between customers' ratings of service and tip size have nevertheless noted that the relationship is "quite small"- "weaker than most people would expect" 46 and even "so weak as to be meaningless." ${ }^{47}$ (On the other hand, and important to understanding

evaluation of service), because people will tip appropriately in order to avoid suffering the "emotional disutility" or social discomfort of disobeying the norm. Azar, Why Pay Extra?, supra note 1, at 257.

${ }^{42}$ Lynn \& McCall, Gratitude and Gratuity, supra note 38, at 204.

${ }^{43}$ Elizabeth L. Post, Emily PosT's ETiQuette 391 (14th ed. 1984); see also Azar, The History of Tipping, supra note 15, at 759 (noting the influence of etiquette guides in establishing the norm).

${ }^{44}$ Post, supra note 43, at 391.

${ }^{45}$ See, e.g., Michael Lynn \& Andrea Grassman, Restaurant Tipping: An Examination of Three "Rational" Explanations, 11 J. ECON. PSYCHOL. 169, 177 (1990) (reporting results of study showing that people "tipped more ... the more favorably they evaluated their service"); Lynn \& McCall, Gratitude and Gratuity, supra note 38, at 209 (reporting results of meta-analysis showing effect of customer ratings of service on tips); Michael Conlin et al., The Norm of Restaurant Tipping, 52 J. ECON. BEHAV. \& ORG. 297, 307 (2003) (reporting study results that "provide evidence that tips do increase with the level of service").

${ }^{46}$ Lynn \& McCall, Gratitude and Gratuity, supra note 38, at 209, 211, 212 (meta-analysis of studies of the service-tipping relationship; although the analysis found a small relationship between tipping and customers' own assessments of service, "tipping was not significantly related to servers' or thirdparties' evaluations of the service").

47 Michael Lynn, Restaurant Tipping and Service Quality: A Tenuous Relationship, Cornell Hotel \& RESTAURANT Admin. Q. 14, 20 (Feb. 2001). Lynn noted further that, while his meta-analysis of tipping studies showed that the average tip "increases only slightly as service ratings increase," the "range in tips at each level of rated service is quite large"-from "5 percent (or less) [to] 20 percent (or more) at any given level of service." Id. at 18. Even if customers base their tips on service quality, it would be rational only for repeat customers to tip, because only one who expects to return to a particular establishment would benefit from the effect of the tip on the server. See, e.g., 
behavior on the other side of the encounter, servers tend to believe that they receive bigger tips when they deliver better service. $)^{48}$ People must have other reasons for tipping. ${ }^{49}$ And, indeed, empirical studies and historical evidence show that, aside from and not necessarily inconsistent

Azar, The Social Norm of Tipping, supra note 2, at 384; Ben-Zion \& Karni, supra note 40 , at 44 . Nevertheless, studies have found little or no difference between the tipping behavior of frequent patrons and customers who do not expect to make future visits. See, e.g., Daniel Kahneman et al., Fairness as a Constraint on Profit Seeking: Entitlements in the Market, 76 AM. ECON. REV. 728, 737 (1986); Lynn \& McCall, Gratitude and Gratuity, supra note 38, at 210; Lynn \& Grassman, supra note 45, at 177; Azar, Why Pay Extra?, supra note 1 , at 260-61. Further, the size of tips given by frequent patrons does not show greater sensitivity to the quality of service than the tips of other patrons, although one would expect it to if customers intend their tips to affect the quality of future service. See Lynn \& Grassman, supra note 45, at 178; see also Ofer H. Azar, Do People Tip Because of Psychological or Strategic Motivations? An Empirical Analysis of Restaurant Tipping, 42 APPLIED ECON. 3039 (2010). Finally, the pattern of occupations in which tipping is or is not prevalent casts doubt on the conventional efficiency explanation, that tipping exists to lower the costs of monitoring and promoting service quality. According to economist Ofer H. Azar, if that were the reason for tipping, one would expect "tipped" occupations (in which tipping is the norm) to be those in which the consumer's ability to monitor service is high (that is, in which the consumer's monitoring costs are low relative to the firm's). Azar's analysis of tipped versus non-tipped occupations, however, found that this relationship does not hold"[t]ipping is not more prevalent in those occupations in which consumers can easily monitor workers, as opposed to the common wisdom to date." Ofer $\mathrm{H}$. Azar, Who Do We Tip and Why? An Empirical Investigation, 37 APPLIED ECON. 1871, 1874 (2005) [hereinafter Azar, Who Do We Tip and Why?].

${ }^{48}$ See Michael Lynn et al., Voluntary Tipping and the Selective Attraction and Retention of Service Workers in the United States: An Application of the ASA Model, 22 INT'L J. HuM. RESOURCE MGMT. 1887, 1893 (2011) [hereinafter Lynn et al., Voluntary Tipping and the Selective Attraction and Retention of Service Workers in the USA].

${ }^{49}$ See Ben-Zion \& Karni, supra note 40 , at 44 (describing their hypothesis regarding the functions served by the practice of tipping as "an explanation for the origin of this norm" but not necessarily of individuals' tipping behavior); MICHAEL LYNN, Tipping in Restaurants and Around the Globe: An Interdisciplinary Review, in HANDBOOK OF CONTEMPORARY BEHAVIORAL ECONOMICS: FoundATIONS AND DEVELOPMENTS 626, 635 (Morris Altman ed., 2006) (distinguishing the "question about why tipping norms exist" from "the question about why individual consumers tip," while noting that "[s]ome of the benefits that motivate individuals to leave tips may also induce societies to adopt tipping norms.") [hereinafter LYNN, Tipping in Restaurants and Around the Globe]. But see Azar, Who Do We Tip and Why?, supra note 47, at 1872, 1876-77 (stating that his analysis of the characteristics of tipped versus nontipped occupations, discussed above, refutes the common explanation for the existence of tipping; offering an explanation for tipping based on psychological utility rather than economic efficiency). 
with the desire to promote service quality, a range of social and psychological motivations explain and influence tipping behavior.

First, the existence of the social norm is itself a key reason why people tip. ${ }^{50}$ That is, people tip in order to comply with the social norm, because disobeying a norm causes people to feel bad about themselves. To disobey a norm goes against both external social pressure to conform and internal motivations to "fulfill the implicit contract." 51 More specifically, it can cause a person to feel embarrassed that other guests or the server know about the lapse. It also can cause internal discomfort by making a person feel that he is being unfair or dishonest in failing to reward the worker's service. By tipping in accordance with the norm, an individual can avoid those negative consequences. ${ }^{52}$

In the United States, where tipping was introduced as a custom imported from Europe during the late nineteenth century, ${ }^{53}$ the practice took hold in large part because it served the economic interests of parties who exerted social pressure to reinforce its observance. Workers who did not receive tips sometimes shunned, insulted, or retaliated against the customer-going so far, for example, as to mark the luggage of hotel guests who did not tip, intending the marks to serve as a warning to service workers the guest would encounter next, who would in turn deny the guest their services. ${ }^{54}$ Employers encouraged tipping because the practice allowed them to pay lower wages or even take a cut of their employees' tips or charge servers "for the privilege to work (and get tips). ${ }^{.55}$ In turn, customers' awareness that lower paid workers relied on tips for their livelihoods increased the customers' feelings of obligation. ${ }^{56}$ Etiquette books and popular culture further cemented the custom by spreading the view that it should be followed. ${ }^{57}$ Once the norm was established, the fact that it was a norm gave people reason to comply.

${ }^{50}$ Somewhat ironically, the stronger the norm, the more its purported purpose may be undermined - that is, "if the norm is to tip a certain percentage of the bill (or a certain amount) regardless of service quality, the incentives of the worker to provide good service are eliminated." Azar, Why Pay Extra?, supra note 1 , at 261 .

${ }^{51}$ Id.; see also Ofer H. Azar, What Sustains Social Norms and How They Evolve? The Case of Tipping, 54 J. ECON. BEHAV. \& ORG 49, 50 (2004) [hereinafter Azar, What Sustains Social Norms and How They Evolve?].

${ }^{52}$ See generally, e.g., Azar, Why Pay Extra?, supra note 1, at 257; Conlin et al., supra note 45 , at 317 .

${ }^{53}$ For discussion of the origins and history of tipping in the United States, see generally SEGRAVE, supra note 15; Azar, The History of Tipping, supra note 15.

${ }^{54}$ See SEGRAVE, supra note 15, at 12-14.

${ }^{55}$ See Azar, The History of Tipping, supra note 15, at 755.

${ }^{56}$ See id. at 756.

${ }^{57}$ See SEGRAVE, supra note 15 , at $43-44$. 
Desire to comply with the social norm alone does not fully account for tipping either, however. Certainly, early practitioners tipped for reasons that did not include complying with a yet-to-be-established norm. Those reasons might have included the desire to insure good service, to show gratitude for a server's efforts, or to show compassion for a worker's meager circumstances. ${ }^{58}$ Likewise, empirical studies of modern tipping behavior show that a range of psychological and social motivations support tipping, that these motivations are interrelated, and that they include the good feelings associated with doing a good deed and the positive image associated with being a tipper.

Rational or not, altruism does seem to be one motivation for tipping. Indeed, because it so closely resembles helping behavior generally, tipping has provided social psychologists with a ready non-laboratory setting in which to study the influence of various situational factors on helping behavior. ${ }^{59}$ People seem to tip at least partly out of compassion for servers' low wages or economic hardship, along with a desire to show gratitude to those who have served them. Even etiquette books that advise withholding a tip for poor service justify tipping in general by pointing out workers' need to supplement their low wages. ${ }^{60}$ Similarly, tipping helps to maintain fairness in the exchange between server and customer, giving the customer peace of mind and enabling him to avoid

${ }^{58}$ See Azar, What Sustains Social Norms and How They Evolve?, supra note 51, at 50 (noting that the historical evidence shows that "people (at least some of them) tip not only because this is the norm but also due to other reasons, such as generosity, desire to impress others, willingness to show gratitude when receiving good service, and empathy for workers who work hard and earn low wages, such as waiters.").

59 See, e.g., Nicolas Guéguen, The Effect of Modeling on Tipping Behavior, 49 STUDIA PSYCHOLOGICA 275, 276 (2007) [hereinafter Guéguen, The Effect of Modeling]; Céline Jacob et al., Effect of Songs With Prosocial Lyrics on Tipping Behavior in a Restaurant, 29 INT'L J. HosPITALITY MGMT. 761, 762-63 (2010); Lynn et al., Consumer Racial Discrimination in Tipping, supra note 25, at 1045, 1056.

${ }^{60}$ See, e.g., Post, supra note 43, at 391 (beginning chapter on tipping by stating, "It would, of course, be ideal if everyone who offered a service of any kind were paid so well that he or she did not have to depend on tips, but this, unfortunately, is not the case. Therefore we must remember that many, many people are dependent on a 'reward' for good service, in addition to their regular salaries."); HARRIETTE COLE, HOW TO BE: A GuIDE TO CONTEMPORARY LIVING FOR AFRICAN AMERICANS 305-06 (1999) (stating that the author thinks about her family members who relied on tips when deciding whom or how much to tip and advising readers to " $[\mathrm{k}]$ now that most people who receive tips are paid very low basic wages and rely on tips as a significant percent of their income."); see also Azar, Who Do We Tip and Why?, supra note 47, at 1877 (concluding that "[t]ipping is created in those occupations in which consumers derive the most psychological utility from it, because they are most likely to feel empathy and compassion and be willing to show their gratitude."). 
the feelings of anxiety and distress that result from being in an uneven relationship. ${ }^{61}$ In addition to deriving good (or avoiding bad) feelings by showing the server her appreciation, the tipper can boost her self-image, because tipping enables the customer to feel generous and "goodhearted." 62

The tipper may be motivated by social reasons as well, such as a desire to elevate himself in the estimation of others. Most immediately, tipping well can gain the approval of the server. Consistent with the hypothesis that people tip for this reason, and after eliminating other reasons (including an interest in the quality of future service), Michael Lynn and Andrea Grassman found that regular customers tip more generously than non-regular customers "because regular customers should value their servers' social approval more than should non-regular customers." ${ }^{63}$ Tipping more might, for example, make regular customers "feel more comfortable in their future visits to the restaurant." ${ }^{.64}$ At the same time, and perhaps paradoxically, tipping can give the customer "a feeling of superiority and power," $" 65$ because the very act of tipping can convey status and class differences between customer and server. For this reason, critics in the late nineteenth and early twentieth centuries denounced tipping as "illegal and un-American"66 - a "form of Flunkyism," "a willingness to be servile for a consideration," and "democracy's deadly foe." ${ }^{\text {" }}$ Customers also might tip to "show off" to others, such as dining companions. For example, leaving a large tip can

${ }^{61}$ See Lynn \& Grassman, supra note 45, at 170-72 and 177-78; Lynn \& McCall, Gratitude and Gratuity, supra note 38, at 211.

${ }^{62}$ Azar, What Sustains Social Norms and How They Evolve?, supra note 51, at 57; see also Azar, The History of Tipping, supra note 15, at 747; Azar, Why Pay Extra?, supra note 1, at 262.

${ }^{63}$ Lynn \& Grassman, supra note 45, at 170-71, 177 (their analysis eliminated other reasons that could explain why regular customers tipped more-and that also could explain why they were regular customers: that "they perceived the food or service to be better than did the non-regular customers."). Lynn and Grassman also failed to find support for the hypothesis that people tip in order to "buy" or affect future service, because the size of tips given by frequent patrons did not show greater sensitivity to the quality of service than the tips of other patrons. $I d$.

${ }^{64}$ Azar, Business Strategy, supra note 3, at 515, 519.

${ }^{65}$ Azar, The History of Tipping, supra note 15, at 747.

${ }^{66}$ SEgRAVE, supra note 15 , at 9.

${ }^{67}$ William Rufus SCOTT, The ItChing Palm: A Study of THE HabIt of TIPPING IN AMERICA 7 (1916). Shades of those sentiments are felt today: As economist David Hemenway has noted, "even when the practice is widespread, a tip may denote a lack of status." HEMENWAY, supra note 41 , at 89 . Hemenway also has pointed out that "[j]obs requiring tipping are often those a servant might perform: personal, menial, low-status services requiring face-to-face contact." Id. at 90 . 
make a person appear both generous and financially well-to-do, thereby increasing his social status and the esteem in which he is held. ${ }^{68}$

That an economic transaction should serve such a range of social and psychological needs and desires is not surprising given the features of the relationship in which that transaction occurs. The next Part examines the complex relationship between the two direct parties to the tipped service encounter.

\section{III. "Transaction Within a Transaction": ${ }^{69}$ The "MiCROCOSMIC"70 RELATIONSHIP BETWEEN TIPPER AND TIPPEE}

However "[r]andom, fleeting, [and] unrenewable"71 the encounter between tipper and tippee may be, it often carries greater complexity, nuance, emotional investment, and consequence than might be expected of an isolated, arms-length transaction. The relationship between tipper and tippee implicates a variety of concerns about each party's worth, the parties' relative power and status, and their interpersonal bond. For the customer, the tip provides the opportunity to recognize the service received, a chance to connect with or criticize the server, and an outlet to express views, emotions, and moods. For the server, especially one who relies on tips for a large share of her livelihood, the tip becomes the focal point of the service encounter, because the tip affects the server's economic well-being and sometimes even her sense of self-worth. ${ }^{72}$

Because tipping is discretionary, the customer has power over the server. Indeed, this power imbalance, based in the customer's freedom and the server's dependence with regard to tips, defines the parties' relationship. $^{73}$ The customer alone determines not just how much, but also whether to tip, because the terms of the "implicit contract" between customer and server are not negotiated and the customer's obligation is

${ }^{68}$ See Azar, Why Pay Extra?, supra note 1, at 262; Azar, What Sustains Social Norms and How They Evolve?, supra note 51, at 57.

${ }^{69}$ Steve Dublanica, Keep the Change: A Clueless TipPer's Quest to BECOME THE GURU OF THE GRATUITY 7 (2010).

${ }^{70} \mathrm{Id}$. at 268 .

${ }^{71}$ Davis, supra note 6 , at 165 (describing the cab driver's relationship with his fare). Of course, some tipping relationships recur, and in those the social and psychological aspects may be even more important to the parties.

${ }^{72}$ E.g., STEVe Dublanica, Waiter RANT: Thanks For THE TIP-CONFESSIONS OF A CYNICAL WAITER 109-10 (2009); Davis, supra note 6, at 161.

${ }^{73}$ See, e.g., Suellen R. Butler \& William E. Snizek, The Waitress-Diner Relationship: A Multimethod Approach to the Study of Subordinate Influence, 3 SOC. WORK \& OCCUPATIONS 209, 209 (1976) (noting that the server work role of waitress "has been defined by the subordinate status occupied by the waitress and the superordinate status occupied by the diner"). 
neither specified nor enforceable. ${ }^{74}$ To the extent that judgments of service quality factor into tipping decisions,$^{75}$ the customer has sole, unchecked ${ }^{76}$ discretion to make that assessment, acting in essence as the server's second "boss." 77 Even if the customer follows a standard guideline, such as the norm of tipping $15-20 \%$ in a restaurant, he has leeway to decide several factors that determine the actual amount of the tip, such as where the tip will fall within the standard percentage range, whether to apply the chosen percentage to the pre- or post-tax amount of the bill, and whether to round the product of those choices up or down to an even dollar figure. ${ }^{78}$ These small decisions can have a significant effect when aggregated over many transactions.

If tipped workers feel that their "compensation depends on the whims of their customers,"79 they are largely correct. Tipping behavior is sensitive to a variety of seemingly random factors, because even in situations where tipping is routine, the individual tipping decision is partly spontaneous. ${ }^{80}$ The tip is "a last second decision" afterthought to the larger transaction-and tipping is "as much of a psychological phenomenon as it is an economic phenomenon."82 Studies have shown that tips can be affected by surprising variables, such as the method of payment; ${ }^{83}$ whether the bill is placed on a tray with or without a credit card insignia, regardless of method of payment; ${ }^{84}$ and what

${ }^{74}$ Azar, Why Pay Extra?, supra note 1, at 255. Indeed, the lack of certainty about what situations call for tipping and the appropriate amount to tip can produce a great deal of anxiety for the customer.

${ }^{75}$ As noted above, service quality has a smaller effect on tips than might be expected. See discussion supra notes 46-47.

${ }^{76}$ The tipper also can choose to conceal-or to display-his tip.

${ }^{77}$ In some settings, customers may exercise control over servers that is "more immediately felt" than the control exercised by management, because customers can "make demands backed by economic force (tips)." Bayard de Volo, supra note 14 , at 349 .

${ }^{78}$ See Ayres et al., supra note 19 , at 1654-55.

${ }^{79}$ DuBlaniCA, supra note 72, at 108.

${ }^{80}$ See Lynn et al., Consumer Racial Discrimination in Tipping, supra note 25, at 1047 ("Tipping decisions have both spontaneous and deliberative components.").

${ }^{81}$ Ayres et al., supra note 19 , at 1618 .

82 David B. Strohmetz et al., Sweetening the Till: The Use of Candy to Increase Restaurant Tipping, 32 J. APPLIED SOC. PSYCHOL. 300, 307-08 (2002).

${ }^{83}$ E.g., Kimberly Garrity \& Douglas Degelman, Effect of Server Introduction on Restaurant Tipping, 20 J. APPLIED SOC. PSYCHOL. 168, 170 (1990) (reporting that diners using credit cards "left substantially larger tips than those paying cash").

${ }^{84}$ Michael McCall \& Heather J. Belmont, Credit Card Insignia and Restaurant Tipping: Evidence for an Associative Link, 81 J. APPLIED PSYCHOL. 609, 609 (1996). 
music is playing in the background. ${ }^{85}$ Perhaps not surprisingly, tipping behavior also varies with the mood of the customer and whether circumstances put the customer in a more positive frame of mind generally. For example, customers have been found to tip more generously when it is sunny outside; ${ }^{86}$ when they receive candy with the check $;{ }^{87}$ and when the server presents them with a "novel, interesting task," such as a word game, at the end of the meal. ${ }^{88}$

Given that customers collectively hold so much control over servers' economic well-being, it is no wonder that servers fixate on the tip in approaching the service encounter. The imbalance between the

${ }^{85}$ Jacob et al., supra note 59 , at 761 ; see also Ronald E. Milliman, The Influence of Background Music on the Behavior of Restaurant Patrons, $13 \mathrm{~J}$. CONSUMER RES. 286, 288 (1986) (finding that, with slow-tempo background music, restaurant patrons stayed longer and consumed more alcoholic beverages-resulting in higher gross margins-compared to patrons in a fastmusic condition).

${ }^{86}$ Michael R. Cunningham, Weather, Mood, and Helping Behavior: Quasi Experiments With the Sunshine Samaritan, 37 J. PERSONALITY \& SOC. PSYCHOL. 1947, 1952-53 (1979); see also Bruce Rind, Effect of Beliefs About Weather Conditions on Tipping, 26 J. APPLIED SOC. PSYCHOL. 137 (1996); Bruce Rind \& David Strohmetz, Effect of Beliefs About Future Weather Conditions on Restaurant Tipping, 31 J. APPLIED SOC. PSYCHOL. 2160 (2001). But see Sean Masaki Flynn \& Adam Eric Greenberg, Does Weather Actually Affect Tipping? An Empirical Analysis of Time-Series Data, 42 J. APPLIED SOC. PSYCHOL. 702 (2011) (finding no statistically significant relationship between sunshine and tipping).

${ }^{87}$ Strohmetz et al., supra note 82 , at 218 . Customers also tip more when the check includes a hand-drawn smiley face or sun or a patriotic message and when they receive with the check a card on which a joke is printed. See Bruce Rind \& Prashant Bordia, Effect on Restaurant Tipping of Male and Female Servers Drawing a Happy, Smiling Face on the Backs of Customers' Checks, 26 J. APPLIED SOC. PSYCHOL. 218 (1996) (finding positive effect on tips of female servers, but not of male servers); Nicolas Guéguen \& Patrick Legoherel, Effect on Tipping of Barman Drawing a Sun on the Bottom of Customers' Checks, 87 PSYCHOL. REP. 223 (2000); Nicolas Guéguen, The Effects of a Joke on Tipping When It Is Delivered at the Same Time as the Bill, 32 J. APPLIED SOC. PSYCHOL. 1955 (2002) [hereinafter Guéguen, The Effects of a Joke on Tipping]; John S. Seiter \& Robert H. Gass, The Effect of Patriotic Messages on Restaurant Tipping, 35 J. APPLIED SOC. PSYCHOL. 1197 (2005). More recent evidence suggests, however, that customers may have "become desensitized" to tactics such as this, perceiving them as "stale" and "part of the standard food-server routine." See id. at 1203.

${ }^{88}$ See Bruce Rind \& David Strohmetz, Effect on Restaurant Tipping of Presenting Customers with an Interesting Task and of Reciprocity, 31 J. APPLIED SOC. PSYCHOL. 1379, 1382 (2001) (citing Bruce Rind, Effect of Interest Arousal on Compliance With a Request for Help, 19 BASIC \& APPLIED SOC. PSYCHOL. 49 (1997)). 
parties puts the server in a vulnerable position, ${ }^{89}$ and if, as is common, the tip is given after the service is provided, makes the relationship between server and customer similar to that of creditor and debtor. Because the server must provide her part of the exchange before she knows how much, or even whether, the customer will reciprocate, she in effect extends credit to the customer during their interaction, with no legal mechanism to insure payment of the debt. ${ }^{90}$ As a consequence, the server must engage in "an act of trust in anticipation of reciprocity," 1 with the ever-present risk of customer default for which she will have no recourse. ${ }^{92}$ Accordingly, it is not uncommon for servers to view customers as a source of threat. One study of restaurant servers' "vulnerability work attitude" found a high level of insecurity in servers" responses to statements such as: "Working for tips is like gambling, there is always a risk involved"; "If most customers could get away with it they would not leave a tip"; and "Most customers I wait on care nothing about the waitress' feelings." 93

To reduce their vulnerability, servers seek ways to increase both the predictability of the outcome of the interaction and their control over that outcome by acting as "experts and managers of [the] service encounter[.]" ${ }^{\text {"94 }}$ As experts, servers predict the tip they are likely to receive from a given customer. ${ }^{95}$ This presumed ability allows servers to engage in "credit selection" to distinguish good credit risks from bad, which enables them to manage their expectations and determine how to approach a given customer. ${ }^{96}$ Over time, servers develop a "kind of specialization" ${ }^{\prime 97}$ on which they rely to draw these distinctions. Steve Dublanica, formerly known by the pseudonym "The Waiter," claims:

${ }^{89}$ Davis, supra note 6, at 158 (referring to the "regulative imbalance" between the parties).

${ }^{90}$ See generally Suellen Butler \& James K. Skipper, Jr., Working for Tips: An Examination of Trust and Reciprocity in a Secondary Relationship of the Restaurant Organization, 22 SoC. Q. 15 (1981) [hereinafter Butler \& Skipper, Working for Tips].

${ }^{91} I d$. at 16.

${ }^{92}$ See id. (elaborating on the server's lack of "recourse or grievance procedure" for customer default).

93 Suellen Butler \& James K. Skipper, Jr., Waitressing, Vulnerability, and Job Autonomy: The Case of the Risky Tip, 7 SOC. WORK \& OCCUPATIONS 487, 49293, 499 (1980) [hereinafter Butler \& Skipper, Waitressing, Vulnerability, and Job Autonomy].

94 Rachel Barkan \& Aviad Israeli, Testing Servers' Roles as Experts and Managers of Tipping Behaviour, SERV. INDUS. J., Nov. 2004, at 91, 92.

95 See generally Bayard de Volo, supra note 14, at 365 (explaining that even regular customers are defined in reference to their tips).

${ }^{96}$ Butler \& Skipper, Working for Tips, supra note 90, at 16.

${ }^{97}$ Id. at 18; see also Barkan \& Israeli, supra note 94. 
In seven years I've developed my own ideas about how and why customers tip. It's gotten to the point where I can tell how much money I'm going to make off a customer within ten seconds of meeting them. It's like I can see the tip percentage floating over their heads. ${ }^{98}$

Assessing a customer's creditworthiness might draw upon a number of clues, such as an evaluation of the customer's mood, the size of the dining party, and whether the diner seems to view the visit as "just another meal" (making the customer a bad credit risk) or as "a celebration or an event." ${ }^{\prime \prime 9}$ Customer attributes, such as apparent age, religiousness, personality, occupation or professional status, and familiarity with or regularity of use of the service in question also can form the basis for the server's prediction. ${ }^{100} \mathrm{Cab}$ driver-turnedsociologist Fred Davis explained this process, cataloguing the "extensive typology of cab users" that drivers might call upon to predict tipping behavior. Davis defined several "types," including "The Sport" (a good tipper), "The Blowhard" (a "false Sport" and bad tipper), "The Businessman" (a fair but not especially big tipper), and "The Lady Shopper" (an undertipper). ${ }^{101}$ Regional, linguistic, and class-based characteristics can brand a customer as a poor tipper as well. In a series of interviews with restaurant servers in a "small, rural southeastern city," for example, many identified "rednecks" as predictably bad tippers. ${ }^{102}$ Of course, as has been noted above and will be elaborated more fully below, service workers often base predictions on the race, ethnicity, or gender of a customer.

Stereotypes about customers' tipping practices often accompany expectations about other aspects of customer behavior, such as whether customers will be difficult and demanding or easygoing and kind. ${ }^{103}$

${ }^{98}$ DUBLANICA, supra note 72 , at 107.

${ }^{99}$ Butler \& Skipper, Working for Tips, supra note 90, at 17.

${ }^{100}$ See, e.g., Michael Lynn \& Benjamin Katz, Are Christian/Religious People Poor Tippers?, 43 J. APPLIED SOC. PSYCHOL. 928 (2013).

${ }^{101}$ Davis, supra note 6, at 161-63.

${ }^{102}$ See Christine Mallinson \& Zachary W. Brewster, "Blacks and Bubbas": Stereotypes, Ideology, and Categorization Processes in Restaurant Servers' Discourse, 16 DISCOURSE \& SOC'Y 787, 794 (2005) [hereinafter Mallinson \& Brewster, "Blacks and Bubbas"].

${ }^{103}$ In one study that asked restaurant servers "open-ended questions designed to ascertain behavioral characteristics of 'good' and 'bad' customers," "good" customers were described as "polite," "patient," "nice," "communicative," "makes eye contact," "not demanding," and "not rude." Zachary W. Brewster, Racialized Customer Service in Restaurants: A Quantitative Assessment of the Statistical Explanatory Framework, 82 Soc. INQUiRY 3, 13 (2012). "Bad" customers "were described as 'rude,' 'demanding,' 'picky,' 'complain a lot,' 'belittling,' 'messy,' and 'runs you."' $I d$. 
Generally, those who are predicted to be poor tippers are also expected to be bad customers. ${ }^{104}$ Difficult customers may be regarded similarly to poor tippers, because, not only do they require greater effort to serve (thereby reducing the relative payoff for the server), but they also impede the server's ability to attend to other customers and to quickly "turn" the table to increase the number of customers served and tips received. ${ }^{105}$

The process of credit selection might lead a worker to dodge the interaction altogether by avoiding a customer who appears to be a bad credit risk. For a cab driver, this might mean driving past a potential passenger, ${ }^{106}$ and for a restaurant server it might mean persuading the host or manager to reassign a table to a different server ${ }^{107}$ or even bargaining with a coworker to take that table. ${ }^{108}$

If the encounter proceeds, servers can draw upon their "expert" evaluations through a second role, as "manager" of the encounter. ${ }^{109}$ As managers, servers strive to "control the reward structure" that governs their work. ${ }^{110}$ That is, they seek to maximize their return, or tips, over their investment, or effort. Workers who depend on tips for a high percentage of their income "are in a sense private entrepreneurs." 11 Although their power to control their work conditions generally is quite limited, ${ }^{112}$ servers have their greatest autonomy "at the point of service delivery, when management is unable to monitor patron/server

${ }^{104}$ See, e.g., Zachary W. Brewster \& Sarah Nell Rusche, Quantitative Evidence of the Continuing Significance of Race: Tableside Racism in Full-Service Restaurants, 43 J. BLACK STUD. 359, 363, 371-73 (2012) [hereinafter Brewster \& Rusche, Quantitative Evidence]; see also Davis, supra note 6, at 161-63.

${ }^{105}$ See Brewster, supra note 103, at 9-10 (discussing servers' "cost-based statistical inferences").

${ }^{106}$ See Ayres et al., supra note 19, at 1635.

${ }^{107}$ See, e.g., Danielle Dirks \& Stephen K. Rice, Dining While Black: Racial Rituals and the Black American Restaurant Experience, in RACE AND ETHNICITY: ACROSS TIME, SPACE, AND DISCIPLINE 255, 270-71 (Rodney D. Coates ed., 2004) [hereinafter Dirks \& Rice, Dining While Black]; see also Mallinson \& Brewster, "Blacks and Bubbas," supra note 102, at 796.

108 See Brewster \& Rusche, Quantitative Evidence, supra note 104, at 363; Dirks \& Rice, Dining While Black, supra note 107, at 270-71.

109 In their study of restaurant servers and experts and managers, Barkan and Israeli found that "servers were not merely predicting their own tip. Instead, they used their prediction to determine how much effort was needed to attain (and exceed) the predicted tip." Barkan \& Israeli, supra note 94, at 105.

${ }^{110}$ Butler \& Snizek, supra note 73 , at 209, 215; see also Davis, supra note 6, at 161.

${ }^{111}$ Bayard de Volo, supra note 14, at 362.

112 See generally Butler \& Skipper, Waitressing, Vulnerability, and Job Autonomy, supra note 93. 
interactions with any degree of efficiency." 113 Although the relationship between service quality and tip size actually is weak, ${ }^{114}$ servers generally perceive the relationship quite differently. A recent survey study found that "the majority of servers believe that their tips are strongly affected by the service they deliver" and that this belief in turn affects their delivery of service. ${ }^{15}$

Servers attempt to reduce their economic uncertainty within the "patron/server interaction" in many ways. One approach is to "get the jump on" customers by engaging in "manipulative maneuvers." "16 For example, restaurant servers might try to influence customers' consumption decisions-most commonly by "upselling," pushing them to order drinks and pricey entrees-in order to increase the size of the bill on which the tip will be calculated. ${ }^{117}$

Another way a server can try to increase the ratio of the expected payoff to the cost of the interaction is by calibrating her service effort. In other words, a server might provide a perceived "good credit risk" with better service and more attention while limiting the time and effort she spends on someone she expects to tip poorly. Studies of server behavior have confirmed that servers follow what the researchers have called a "self-fulfilling prophecy" strategy, by which a "prediction of [a] large tip[] . . . lead[s] to increased service effort and ... [a] prediction of [a] small tip[] . . . lead[s] to decreased service effort." 118 Thus, a restaurant

${ }^{113}$ Zachary W. Brewster \& Christine Mallinson, Racial Differences in Restaurant Tipping: A Labour Process Perspective, 29 SERV. INDUS. J. 1053, 1061 (2009). Recall that management's limited ability to monitor service quality is one of the key factors that led to the practice of tipping, by which customers have been delegated authority to evaluate and reward service.

${ }^{114}$ See discussion supra notes 46-47.

115 Robert J. Kwortnik et al., Buyer Monitoring: A Means to Insure Personalized Service, 46 J. MARKETING RES. 573, 577, 580 (2009) (reporting results of online survey of servers across forty-eight states in the U.S., with data from 1189 servers). This belief may stem in part from service workers' motivation "to perceive a strong relationship between their service efforts and tip rewards because they do not want to view themselves as the undeserving recipients of charity" and people's tendency to "believe that they have more control over events than they actually do." $I d$. at 575 .

${ }^{116}$ Butler \& Snizek, supra note 73, at 210,213.

117 See generally id. (discussing the importance of such "promotional activity" for restaurant servers). Workers in other service occupations have their own "diverse tactics and stratagems" for increasing tips, as well. For example, Davis has noted that cab drivers might even go so far as to invent service charges to offset the risk of being stiffed. See Davis, supra note 6, at 163-64.

${ }^{118}$ Barkan \& Israeli, supra note 94, at 105 (measuring service effort using "server-initiated approaches," id. at 99 \& 106 n.1, meaning "the number of times a server initiated attendance" (i.e., asking whether customers are enjoying the food, inquiring if any service is needed, etc.) $i d$. at 96 ). In a recent survey of 
customer who is expected to tip well will receive frequent visits from the server, asking whether she is enjoying the food or needs anything more, ${ }^{119}$ while customers who are expected to tip poorly "just don't get the service." 120

Servers also try to manage the encounter by drawing on a wide repertoire of relationship-enhancing tactics calculated to maximize the tip. ${ }^{121}$ As Dublanica ("The Waiter") put it, "A good waiter needs to push the right buttons in order to seduce a customer." 122 In fact - and unlike objective indicators of service quality - small, friendly gestures that enable the server to build a social and emotional connection with the customer do have a significant effect on tips. Numerous research studies have shown the significant influence of various such techniques, some of which have been found to increase tips by an average of 20 percent, and some by as much as 40 percent or more. ${ }^{123}$ The effect of these tactics on tipping reflects common responses to a range of social cues and is consistent with social behavior in other contexts. ${ }^{124}$

servers at full-service restaurants, respondents reported both that they sometimes provided poor service to customers they thought would not tip well ( $42.1 \%$ admitted to sometimes, $5.6 \%$ to often, and $1.5 \%$ to always doing this) and that they believed their coworkers also did (59.7\% sometimes, $16.3 \%$ often, and $2.6 \%$ always). Brewster \& Rusche, Quantitative Evidence, supra note 104, at $374-75$.

119 See Barkan \& Israeli, supra note 94, at 96.

${ }^{120}$ Karla Erickson, To Invest or Detach? Coping Strategies and Workplace Culture in Service Work, 27 SYMBOLIC INTERACTION 549, 557 (2004) (statement of restaurant worker) ("The people who don't tip right, they just don't get the service, it's not that we don't serve them, but we know. I don't work for free. I mean I'm not there to have fun.").

${ }^{121}$ See Michael Lynn \& Michael McCall, Techniques for Increasing Servers' Tips: How Generalizable Are They?, 50 CORNELL HosPITALITY Q. 198, 201-07 (2009) [hereinafter Lynn \& McCall, Techniques for Increasing Servers' Tips] (reporting results of nationwide internet survey concerning restaurant servers' frequency of use of specific techniques for increasing tips).

${ }^{122}$ DuBLANICA, supra note 72, at 113.

${ }^{123}$ Lynn \& McCall, Techniques for Increasing Servers' Tips, supra note 121, at 199. Based on their internet survey of a "large heterogeneous sample of servers working at a large number of different restaurants from across the country," Lynn and McCall concluded that the effects of tip-enhancing techniques are generalizable and "not limited to the small samples of servers and restaurants used in previous experimental research" such as the studies cited in this article. Id. at 207. See also W. Michael Lynn, MegaTips2: Twenty Tested Techniques to Increase Your Tips, 2 CORNELl HosPITALITY TOOLS 4, 21 (2011) [hereinafter Lynn, MegaTips2].

${ }^{124}$ In particular, tipping can be viewed as a form of helping behavior. See supra note 59 . 
Customers respond with significantly higher tips when servers behave in a friendly way or personalize the service or themselves-for example, when servers greet customers with large, open-mouthed, "affiliative" smiles; introduce themselves by name; or wear something decorative or unusual. ${ }^{125}$ Indeed, many of the mood-boosting gestures associated with larger tips - handwriting "thank you" or drawing a sun or "smiley" face on, or giving candy with, the check-are effective in part because they allow the server to connect with the customer. ${ }^{126}$ Customers also tip significantly more when servers give them a reason to feel a sense of common identity or shared bond, for example by writing a patriotic message ("United We Stand") on the check. ${ }^{127}$ Another way to elicit higher tips is to build rapport with customers by engaging in socially "immediate" behaviors, such as briefly touching the customer on the shoulder or hand, standing close to the customer, or squatting next to the table so that the server's eyes are in line with the customer's. ${ }^{128}$ Other strategies ingratiate the server with the customer by making her feel important, smart, or attractive: saying the customer's name; repeating or complimenting a restaurant customer on her order after she

${ }^{125}$ See Kathi L. Tidd \& Joan S. Lockard, Monetary Significance of the Affiliative Smile: A Case for Reciprocal Altruism, 11 BULL. PSYCHONOMIC SOC'Y 344 (1978); Garrity \& Degelman, supra note 83, at 187-88; JeriJayne W. Stillman \& Wayne E. Hensley, She Wore a Flower in Her Hair: The Effect of Ornamentation on Nonverbal Communication, 8 J. APPLIED COMM. RES. 31 (1980). But see Lynn \& McCall, Techniques for Increasing Servers' Tips, supra note 121, at 205 (noting that server's introducing herself by name can have a negative effect, probably if it is viewed as "annoying" or as part of a "script").

${ }^{126}$ See Bruce Rind \& Prashant Bordia, Effect of Server's "Thank You" and Personalization on Restaurant Tipping, 25 J. APPLIED SOC. PSYCHOL. 745 (1995) [hereinafter Rind \& Bordia, Effect of Server's "Thank You" and Personalization]; Rind \& Bordia, supra note 87, at 218; Guéguen \& Legoherel, supra note 87; Strohmetz et al., supra note 82.

${ }^{127}$ Seiter \& Gass, supra note 87 , at 1197 . Note, however, that this tactic may have proven effective in large part because of the time period during which it was tested, shortly after the terrorist attacks of Sept. 11, 2001. See id. at 1199, $1202-03$.

${ }^{128}$ See, e.g., April H. Crusco \& Christopher G. Wetzel, The Midas Touch: The Effects of Interpersonal Touch on Restaurant Tipping, 10 PERSONALITY \& SOC. PSYCHOL. Bull. 512 (1984); Stephen F. Davis et al., Restaurant Servers Influence Tipping Behavior, 83 PSYCHOL. REP. 223 (1998); Jacob Hornick, Tactile Stimulation and Consumer Response, 19 J. CONSUMER RES. 449 (1992); Céline Jacob \& Nicolas Guéguen, The Effect of Physical Distance Between Patrons and Servers on Tipping, 36 J. HOSPITALITY \& TOURISM RES. 25 (2012); Reneé Stephen \& Richard L. Zweigenhaft, The Effect on Tipping of a Waitress Touching Male and Female Customers, 126 J. Soc. PsYCHOL. 141 (1986). Note, however, that members of different groups may react differently to the server's touching or standing close to them. See, e.g., Jacob \& Guéguen, supra; Gina Leodoro \& Michael Lynn, The Effect of Server Posture on the Tips of Blacks and Whites, 37 J. APPLIED SOC. PSYCHOL. 201 (2007). 
gives it; or, for a hair stylist, complimenting the customer's appearance or choice of hairstyle. ${ }^{129}$ Entertaining customers also brings bigger tips. As noted above, studies have found that customers tip more generously when they are given an "interesting task" or receive a joke along with their check. ${ }^{130}$

Customers sometimes tip as a way to reciprocate a server's kindness. This motivation explains why customers leave significantly bigger tips after receiving a check with a handwritten "thank you," 131 a fancy, foilwrapped chocolate candy, ${ }^{132}$ or a helpful message (informing them of an

${ }^{129}$ See, e.g., Lynn, MegaTips2, supra note 123, at 15 (citing Karen M. Rodrigue, Tipping Tips: The Effects of Personalization on Restaurant Gratuity (1999) (unpublished master's thesis, Emporia State University)); Rick B. van Baaren et al., Mimicry for Money: Behavioral Consequences of Imitation, $39 \mathrm{~J}$. EXPERIMENTAL SOC. PSYCHOL. 393 (2003); John S. Seiter, Ingratiation and Gratuity: The Effect of Complimenting Customers on Tipping Behavior in Restaurants, 37 J. APPLIED Soc. PsYCHOL. 478 (2007); John S. Seiter \& Eric Dutson, The Effect of Compliments on Tipping Behavior in Hair-Styling Salons, 37 J. APPLIED SOC. PSYCHOL. 1999 (2007); John S. Seiter \& Harry Weger, Jr., The Effect of Generalized Compliments, Sex of Server, and Size of Dining Party on Tipping Behavior in Restaurants, 40 J. APPLIED SOC. PSYCHOL. 1 (2010). Note, however, that as is the case with other tip-enhancing techniques, these can backfire. For example, servers should be wary of what Seiter and Weger have called the "slime effect": the negative effect on tips of complimenting customers on their orders if the dining party numbers more than four, perhaps because the compliments seem insincere. See Seiter \& Weger, supra, at 9.

${ }^{130}$ See Guéguen, The Effects of a Joke on Tipping, supra note 87; Rind \& Strohmetz, Effect on Restaurant Tipping of Presenting Customers With an Interesting Task, supra note 88.

${ }^{131}$ Rind \& Bordia, Effect of Server's "Thank You" and Personalization, supra note 126.

${ }^{132}$ See Strohmetz et al., supra note 82. One study of the effect of differences in how candy is offered reveals vividly the influence on tipping of the desire to reciprocate. In that study, customers tipped more when they were offered their choice of one piece of candy from a basket than when they were not, and even more when they were offered their choice of two pieces. They tipped the most of all when the server initially offered them one piece and then, just as she was leaving the table, stopped to offer them an additional piece. The last two situations differed only in the manner in which the candy was offered: In both scenarios, the customer received two pieces of candy, but in the last the server seemed to be more generous, "to be making an extra, personal," id. at 304 , and "seemingly spontaneous gesture of providing each customer an additional opportunity to select a piece of candy from the basket," id. at 306 . That customers tipped significantly more in the " $1+1$ " than the "2-piece" condition indicates that, beyond the positive impression a generous server makes on diners or the boost to their mood the "unexpected treat of candy" brings, "it is reciprocity that underlies this candy effect." $I d$. at 306-07. 
upcoming dinner special ${ }^{133}$ or a good weather forecast, ${ }^{134}$ for example).

For customers, these rapport-building gestures add value to the service, by providing "the feel of simple civility or caring when delivered in a face-to-face context."'135 For servers, performing this "value added" service is work-work that sociologist Arlie Hochschild has named "emotional labor" because it "requires one to induce or suppress feeling in order to sustain the outward countenance that produces the proper state of mind in others," such as "being cared for in a convivial and safe place." 136 Emotional labor can bring rewards to the server as well as the customer, as some servers welcome the social exchange and may even develop friendships with regular customers. ${ }^{137}$ But even for workers who seek out and find pleasure in their connections with customers-and perhaps more so for those who prefer to maintain emotional and psychological distance from customers while doing this work-emotional labor can take a toll. ${ }^{138}$ No matter how friendly or

${ }^{133}$ See Bruce Rind \& David Strohmetz, Effect on Restaurant Tipping of a Helpful Message Written on the Back of Customers' Checks, 29 J. APPLIED SOC. PSYCHOL. 139 (1999).

${ }^{134}$ Rind \& Strohmetz, Effect of Beliefs About Future Weather Conditions on Restaurant Tipping, supra note 86, at 2160 (noting reciprocity as an alternative explanation to the positive mood induced by receiving a forecast of good weather). Receiving a forecast of bad weather, on the other hand, did not lead to increased tips; perhaps such information was viewed as not being useful and therefore as not calling for reciprocation. See id. at 2163-64.

${ }^{135}$ Brewster \& Mallinson, supra note 113, at 1053, 1061 (quoting K. ALBRECHT \& R. ZemKe, SERVICE AMERICA: DoINg businesS IN THE NEW ECONOMY 20 (1985)).

${ }^{136}$ ARLIE Russell Hochschild, The Managed Heart: Commercialization OF HUMAN FEELING 7 (1983). In the quoted sentence, Hochschild was writing specifically of the emotional labor performed by flight attendants, whose work (albeit untipped) in many ways resembles that of many workers in tipped occupations. For example, Hochschild identified waitresses and waiters among those who perform emotional labor. Id. at 11.

${ }^{137}$ See, e.g., id. at 35 (describing "deep acting" as a situation where "display is a natural result of working on feeling; the actor does not try to seem happy or sad but rather expresses spontaneously, ..., a real feeling that has been selfinduced); Erickson, supra note 120, at 549, 560-62 (discussing interviews with restaurant servers who "invested" in their work by seeking to develop connections with customers and described the pleasure they derived from those relationships; comparing this approach to the "deep acting" described by Hochschild).

${ }^{138}$ See HoCHSCHILD, supra note 136, at 33 (describing "surface acting" as "disguising what we feel, ... pretending to feel what we do not.... In surface acting we deceive others about what we really feel, but we do not deceive ourselves."); Erickson, supra note 120, at 557-60 (describing the "detachment" strategy adopted by some restaurant servers, comparing this approach to the "surface acting" described by Hochschild). 
caring the interaction between customer and server, it still resides within a relationship of unequal status and power, wherein the customer is freer and the server more constrained in their "rights to feeling and display." 139 Indeed, the costs to the worker of doing emotional labor may be more draining than the physical demands of the job. Remarking on a series of interviews with restaurant servers, many of whom chose to "invest" in their relationships with customers, sociologist Karla Erickson noted that, "when discussing the difficulties of waiting tables, they emphasized almost exclusively emotion management rather than tired feet or dirty aprons." 140

The tip itself is emblematic of the inequality in entitlement and power between the parties, and it can loom large not just in the server's economic well-being, but also in his emotional state and sense of selfworth. Getting a large tip may be cause for celebration and a boost to the server's ego. Being tipped poorly, on the other hand, may have an outsized negative effect. Dublanica, for example, has described the "emotional pain and embarrassment of getting a bad tip" and the sting he felt when a customer stated he was "not worth" the standard gratuity that was automatically added to the check of a large party. ${ }^{141}$

Being "stiffed" is worst of all. It is both a humiliation and a reminder of the server's vulnerability: "It might be noted that 'getting stiffed' is rarely an event that is shared with other waitresses. It is not a source of prestige for the waitress, rather it is an indicator of the waitress' inability to control the work situation." 142 And, as Dublanica points out after relating the story of a coworker who broke down in tears after being stiffed, "[t]he financial consequences of not being tipped suck, but there's an emotional and psychic toll as well. Not getting a tip hurts." ${ }^{143}$

\section{SITUATIONAL DISCRIMINATION AND SELF-FULFILLING STEREOTYPES IN TIPPED TRANSACTIONS}

The parties' respective interests, the characteristics of the tipping transaction, and the social dynamics of the service encounter combine to create a situation that is ripe for the influence of social stereotypes and

139 As Hochschild explains, "[w]here the customer is king, unequal exchanges are normal, and from the beginning customer and client assume different rights to feeling and display. The ledger is supposedly evened out by a wage." HOCHSCHILD, supra note 136 , at 86 . Or, presumably, a tip.

${ }^{140}$ Erickson, supra note 120 , at 553.

141 DUBLANICA, supra note 72, at 109-10.

142 Butler \& Snizek, supra note 73, at 212; see also Butler \& Skipper, Working for Tips, supra note 90, at 16 (comparing this situation to "[a] default on credit" which is "an absolute loss for the waitress").

${ }^{143}$ DUBLANICA, supra note 72, at 109 (emphasis in original). 
bias on both sides. ${ }^{144}$ Indeed, tipping presents the very sort of situation that promotes a kind of discrimination that is likely to occur at a time like the present, when overt prejudice is less acceptable and common than in the past but "aversive racism"145 and implicit bias ${ }^{146}$ are prevalent: the intractable, hard to detect, and often unintentional kind of discrimination that I have referred to previously as "situational." 147 The features and structure of the tipped service encounter create an opening for discrimination by both customer and server because the standards for behavior on both sides are largely ambiguous. Tipped service interactions also present favorable conditions for the influence of social group stereotypes, both because the customer-server relationship is often formed with little opportunity for the parties to learn about one another as individuals and because the parties' respective roles and objectives require them to make decisions for which stereotypes often provide ready guidance.

"Situational discrimination" describes a paradox of modern day discrimination. Its emergence is highly dependent on the situation, but it is more likely to occur when racial issues are obscured than when they are apparent. Consequently, "discrimination is most likely to occur in situations in which it is least likely to be detected"148 — by observers, the subject of discrimination, or even the actor himself. In particular, social psychological studies have found that people tend to discriminate in situations that are "normatively ambiguous"- that is, where right and wrong behavior are not clearly distinguishable - even if they would not do so in situations that are normatively clear. The explanation for this counterintuitive effect seems to be that people are more mindful of their egalitarian ideals and more careful to guard against acting on prejudice when racial issues are clear and conspicuous. Further, because right and wrong are easier to identify in such a situation, discriminatory actions are easier to recognize and avoid as well. When a situation is normatively ambiguous, on the other hand, people often do not guard against, but instead act on, their prejudices. ${ }^{149}$

Normatively ambiguous situations can take two forms: First, a situation is normatively ambiguous when there is no clear "right" or

${ }^{144}$ See Ayres et al., supra note 19, at 1663.

${ }^{145}$ See generally SAMUEL L. GAERTNER \& JOHN F. DOvidio, The Aversive Form of Racism, in PREJUdiCE, DisCriminATION, AND RACISM 61 (1986).

${ }^{146}$ See generally Kristin A. Lane et al., Implicit Social Cognition and Law, 3 ANN. REV. L. \& SoC. SCI. 427 (2007).

${ }^{147}$ For fuller discussion of situational discrimination and self-fulfilling stereotypes, see LU-IN WANG, Discrimination BY DEFault: How RaCism BECOMES ROUTINE 25-81 (2006).

${ }^{148}$ Id. at 17.

${ }^{149}$ See id. at 37 . For discussion of three possible explanations for situational discrimination, see $i d$. at $42-43$. 
"wrong" thing to do, such as when an individual must decide whether to hang up on someone who has dialed a wrong number, or instead to stay on the line and try to help the caller find the intended party, or when a person must decide whether to stop and help or instead walk past a shopper who is struggling with a torn shopping bag. Researchers found that subjects faced with these situations were more likely to help a white person than a black person, probably because choosing not to help in such a situation is not clearly wrong or "racist." 150 The second kind of normative ambiguity arises when a negative decision can be justified on some basis other than race. This sort of ambiguity is illustrated by studies of simulated employment and college admissions decisions, in which researchers found that subjects were more likely to treat white and black applicants similarly if their qualifications were consistently strong or weak but to favor white applicants when presented with black and white candidates who had "mixed" qualifications (some strong and some weak). In the mixed or ambiguous case, presumably the negative points in the black applicant's file provided a non-racial justification for favoring majority over minority group candidates. ${ }^{151}$

Social stereotypes are another feature of the tipped service encounter that can influence its outcome, often without being noticed. Group-based stereotypes are more than just (frequently inaccurate) generalizations about groups of individuals. They can also guide social interactions by directing a particular path for performance or behavior. ${ }^{152}$ Stereotypes exert their influence before the parties even meet, by shaping their expectations about members of stereotyped groups. Once the parties come into contact, stereotypes can color their perceptions and interpretations of one another through a process of perceptual confirmation. Furthermore, a stereotyped individual might unwittingly (and sometimes intentionally) "confirm" even an erroneous stereotype through his behavior, because stereotypes can lead one person to approach another in a stereotype-influenced way that "boxes in" the other person, limiting his or her options for responding. Numerous experimental studies have confirmed the behavioral confirmation of interpersonal expectancies (of which stereotypes are one variety),

${ }^{150}$ See id. at 37 (citing Samuel L. Gaertner, Helping Behavior and Racial Discrimination Among Liberals and Conservatives, 25 J. PERSONALITY \& SOC. Psychol. 335 (1973); Lauren G. Wispé \& Harold B. Freshley, Race, Sex, and Sympathetic Helping Behavior: The Broken Bag Caper, 17 J. PERSONALITY \& SOC. PSYCHOL. 59 (1971)).

${ }^{151}$ See WANG, supra note 147, at 40 (citing John F. Dovidio \& Samuel L. Gaertner, Aversive Racism and Selection Decisions: 1989 and 1999, 11 PSYCHOL. SCI. 319 (2000)). These outcomes have been replicated in several additional studies of normative ambiguity, many of which have focused on helping behavior, to which tipping is often compared. See, e.g., WANG, supra note 147 , at $38-42$.

${ }^{152}$ See generally WANG, supra note 147, at 52. 
showing, for example, that 'individuals' expectations of others--that the other was hostile, extroverted, sociable, or even guilty of a crimeactually induced those others to behave in conformity with those expectations, thereby 'confirming' them, even when the expectations were wholly created by the experimenters." 153

This self-fulfilling process is not inevitable, of course. Some people may be less influenced by stereotypes, some people may be more aware of and resistant to their influence, and in some cases other influences, including the parties' particular goals, might push the parties' behavior in other directions. Nevertheless, service encounters generally, and tipped service encounters particularly, are among the more likely interactions to promote the influence and confirmation of stereotypes-especially race and gender stereotypes - because of the structure and characteristics of those encounters. For one thing, race and gender stereotypes are among the most powerful interpersonal expectations; they "tend to be held with more certainty than other interpersonal expectancies because they are shared and validated by others - often by society at large"-and are "automatically activated and chronically accessible." 154

In addition, the structure and features of tipped service transactions promote both parties' reliance on and confirmation of race and gender stereotypes. First, both parties are simultaneously "perceivers" and "targets": Each is in a position to assess the other and is subject to being assessed by the other, albeit for different purposes. Second, the circumstances of the transaction-the power differential between customer and server, the parties' respective roles in and goals for their interaction, the limitations placed on their behavior by the standard script for their encounter, and the lack of time, attention, and motivation to resist the influence of stereotypes-frequently combine with the normative ambiguity of the situation to tip it into discrimination.

\section{A. THE NORMATIVELY AmbiguOUS SITUATION OF TIPPING}

Tipping is normatively ambiguous in both of the ways that have been found to facilitate discrimination. ${ }^{155}$ First, with tipping there is often no clear right or wrong decision. As noted above, the norm in many service settings is not certain, sometimes on the question of whether a tip is called for and, more often, on how much is an

$153 \mathrm{Id}$. at 60 .

${ }^{154}$ Id. at $68-69$.

${ }^{155}$ See discussion supra notes 150-51. In addition, normative ambiguity has been found to promote discrimination in both spontaneous and deliberative decision making, see WANG, supra note 147, at 38-42, and tipping encompasses both, see Michael Lynn \& Michael Sturman, Is the Customer Always Right? The Potential for Racial Bias in Customer Evaluations of Employee Performance, 41 J. APPLIED SOC. PSYCHOL. 2312, 2314 (2011). 
appropriate amount to tip. ${ }^{156}$ Moreover, given the discretion accorded to tippers, the customer usually need not justify a particular decision. And even if one were asked to explain a tip, non-discriminatory justifications are readily available, a factor that gives rise to the second kind of normative ambiguity: The quality of the service, the quality of the food, the type of establishment, ${ }^{157}$ even the customer's mood, for example, all might serve as acceptable reasons for choosing to tip a particular amount.

A recent study of race discrimination in restaurant tipping by Lynn and his colleagues found support for the effect on tips of situational ambiguity and implicit negative attitudes toward black servers. The study's principal finding was that restaurant customers in Mississippi tipped black servers significantly less than white servers $(17.5 \%$ vs. $20.7 \%$ and $14.6 \%$ vs. $19.4 \%$, depending on the size of the dining party), and that black customers as well as white discriminated in this way. ${ }^{158}$ Through additional analysis, the researchers determined that the race effect on tips was not attributable to differences in the actual quality of service provided by servers of different races. ${ }^{159}$ On the other hand, race effects were moderated by two other variables - size of dining party and individual ratings of service quality - in ways that are consistent with the operation of situational discrimination.

${ }^{156}$ Even settings with relatively well-defined expectations leave room for discretion on a number of matters: what percentage to tip, whether to apply that percentage to the pre- or post-tax bill, and whether to round the tip up or down to an even dollar figure. See discussion supra notes 74-78. In their study of the tipping of cab drivers, Ayres and his co-authors observed that $54.8 \%$ of the tips in their data set had been rounded by the passenger to the nearest integer and noted that " $[\mathrm{t}]$ hese rounded observations, to our minds, are prime candidates for unconscious discrimination." Ayres et al., supra note 19, at 1654-55. While cautioning that this evidence is "tentative," the authors reported that their analysis of the data provided "a bit of evidence to support this form of unconscious discrimination. Overall, passengers were $6 \%$ more likely to round up rather than down with a white driver than with a black driver." Id. at 1655 .

${ }^{157}$ See, e.g., David Neumark, Sex Discrimination in Restaurant Hiring: An Audit Study, 111 Q. J. ECON. 915, 931-32 (1996) (reporting "large positive earnings differentials in high-price restaurants relative to both medium- and low-price restaurants").

${ }^{158}$ Lynn et al., Consumer Racial Discrimination in Tipping, supra note 25, at 1054.

${ }^{159} \mathrm{Id}$. at 1055 . Although the analyses reported in this article were "not indicative of race effects on service evaluations," Lynn \& Sturman, supra note 155 , at 2315 , two of the authors later reanalyzed the data to examine the potential for racial bias in customer evaluations of server performance, id. at 2314. See discussion of that reanalysis, infra notes 177-79. 
First, the size of the dining party affected the magnitude of the race effect. ${ }^{160}$ That is, the difference in tips received by white versus black servers was significantly greater with larger dining parties:

Groups of one or two diners tipped White servers an average of $20.7 \%$ of the bill and tipped Black servers an average of $17.5 \%$ of the bill; while parties of three or more tipped White servers an average of $19.4 \%$ of the bill and tipped Black servers an average of $14.6 \%$ of the bill. ${ }^{161}$

This result is consistent with the "diffusion of responsibility,"162 a social psychological phenomenon that has been found both to affect tipping behavior generally and to promote race discrimination in helping behavior, to which tipping has been compared. ${ }^{163}$ That is, some studies have found evidence of a diffusion effect in restaurant tipping, with larger dining parties leaving lower percentage tips than individual diners or smaller parties. ${ }^{164}$ In other helping contexts, the presence of others has been found to promote race discrimination by providing a non-racial justification for declining to come to the aid of a black person in situations where white victims were helped more readily. ${ }^{165}$ The study by Lynn and his colleagues of race effects on tipping encompasses both of these situations and indicates that "diffusion of responsibility would

${ }^{160}$ Lynn et al., Consumer Racial Discrimination in Tipping, supra note 25, at 1054.

161 Id.

162 Research studies have confirmed the effect on individuals' helping behavior of the presence of other potential helpers. An individual's awareness that others are available to help a person in need tends to dilute or diffuse each person's sense of responsibility to act. This effect might result from the individual's reasoning that someone else will help or would be more competent to help. It also might result because the inaction of others constructs the situation as one in which the victim's situation is not serious enough to warrant intervention or in which it would be inappropriate to intervene. See generally John M. Darley \& Bibb Latané, Bystander Intervention in Emergencies: Diffusion of Responsibility, 8 J. Personality \& SOC. PsyChOL. 377 (1968).

163 See supra note 59.

${ }^{164}$ See, e.g., Stephen Freeman et al., Diffusion of Responsibility and Restaurant Tipping: Cheaper by the Bunch, 1 Personality \& SOC. PsychOL. Bull. 584 (1975). Lynn and his colleagues, however, point out that "it is not clear how much the responsibility for tipping is diffused in large parties" because the effect that Freeman et al. "attributed to diffusion of responsibility, can instead be a statistical artifact common to correlations of ratio variables like tip percentage." Lynn et al., Consumer Racial Discrimination in Tipping, supra note 25, at 1048 n.2 (citing Michael Lynn \& Charles F. Bond, Jr., Conceptual Meaning and Spuriousness in Ratio Correlations: The Case of Restaurant Tipping, 22 J. APPLIED SOC. PSYCHOL. 327 (1992)).

${ }^{165}$ See generally WANG, supra note 147, at 39-40 (describing studies). 
provide a non-racial basis for leaving small tips and, thus, would free tips to reflect the tippers' negative implicit attitudes toward Black servers." 166

The second variable in the study that influenced the race effect was customers' ratings of service quality. The study found that white servers received much higher tips for what customers perceived as perfect service than they did for less than perfect service, while black servers' tips did not differ with the level of service:

For White servers, tips increased from $16.8 \%$ of the bill size when service was rated less than perfect to $23.4 \%$ of the bill size when service was given a perfect rating. However, for Black servers, tips were $16.6 \%$ of the bill size for both perfect and less than perfect service ratings. ${ }^{167}$

In other words, white servers received a far greater reward for perfect service, while black servers' tips were unaffected by the level of service they provided. This result, too, is consistent with the operation of situational discrimination, although the race effect manifested in a direction opposite of what the researchers had expected. ${ }^{168}$ The researchers hypothesized that the race effect would be greater with lower ratings of service quality. They reasoned that a customer's assessment that service was poor could provide a nonracial justification for his giving a smaller tip to a black server than he would to a white server. ${ }^{169}$ Nevertheless, the actual finding that the server race effect was stronger at higher levels of perceived service quality, though unexpected, ${ }^{170}$ was not inconsistent with the aversive racism explanation. The researchers speculated that the opposite race effect materialized because lower ratings of service quality are themselves

consistent with negative stereotypes of Black workers, so saying that you gave a Black server a small tip because the service was not excellent does not diminish the appearance of racism. Thus, tippers seeking to avoid the appearance of racism may have been reluctant to lower tips to Black servers when the service was less than excellent. ${ }^{171}$

${ }^{166}$ Lynn et al., Consumer Racial Discrimination in Tipping, supra note 25, at 1056.

${ }^{167}$ Id. at 1054 .

$168 \mathrm{Id}$. at 1056 .

${ }^{169} \mathrm{Id}$. at 1048 .

${ }^{170} \mathrm{Id}$. at 1056 .

${ }^{171} I d$. 
With white servers, on the other hand, diners would have no compunctions about tying tips to service quality, so white servers received a wider range of tips that varied with perceived service quality. ${ }^{172}$ It might also be that the lower end of the expected tipping range of $15-20 \%$ sets the floor below which a tip cannot go without raising a question as to the customer's motivations, so customers would not feel justified in giving a tip below that floor regardless of service quality. ${ }^{173}$ (Note that tips for both black and white servers bottomed out at about the same level regardless of service ratings. ${ }^{174}$ ) Customers might also have been inclined to reward white servers for excellent service while not adjusting their tips to black servers upwards in a similar fashion because of a pro-white bias of the kind that has been documented in studies of implicit racial attitudes. ${ }^{175}$ That is, perhaps customers simply were not motivated to tip black servers above the lower boundary regardless of how much effort those servers put into providing service, but were motivated to reward a white server who went above and beyond. In that case, the excellent service rating could provide a nonracial justification for favoritism towards white servers. ${ }^{176}$ As a result, investing greater effort was more rewarding for white than for black servers.

The differential effect of service ratings on tips for white versus black servers may have been exacerbated by another way in which situational discrimination manifests-in the underlying customer evaluations themselves. While the study indicates that the same evaluation of service leads to different sized tips for white and black servers, a separate analysis of its data also indicates that customers may evaluate restaurant service differently for servers of different races. In particular, customers in the study (both black and white) tended to evaluate servers of their same race more favorably than servers of a different race. In addition, this same-race bias in evaluations reflected a

${ }^{172} I d$.

${ }^{173}$ This potential explanation represents the author's speculation. In correspondence suggesting this possible explanation, the lead author of the study in question responded that it is "a reasonable alternative explanation for our interaction." Email from W. Michael Lynn to Lu-in Wang (Apr. 19, 2012 3:32:07 PM) (on file with author).

${ }^{174}$ Lynn et al., Consumer Racial Discrimination in Tipping, supra note 25, at 1054.

${ }^{175}$ See, e.g., Brian A. Nosek et al., Harvesting Implicit Group Attitudes and Beliefs from a Demonstration Web Site, 6 Group DyNAMICS: THEORY, RES. \& PRAC. 101, 105-06 (2002).

${ }^{176}$ This potential explanation represents the author's speculation. In correspondence suggesting this possible explanation, the lead author of the study in question responded that it is "a reasonable alternative explanation for our interaction." Email from W. Michael Lynn to Lu-in Wang (Apr. 19, 2012 3:32:07 PM) (on file with author). 
"situational" influence that was consistent with the theory of aversive racism. ${ }^{177}$ Both black and white customers favored servers of their own race in ratings of promptness and attentiveness-"situational" dimensions of service that are perceived as being affected by factors outside the server's control, such as a slow kitchen staff-but not on the "dispositional" dimensions or "personal characteristics" of server appearance and friendliness, on which customer ratings showed no racial bias. ${ }^{178}$ This study suggests that racial bias might influence customer evaluations of service workers' performance in other settings as well, at least on dimensions where the customer can more easily attribute her evaluation to non-personal, and therefore non-racial, elements of performance. Accordingly, the study suggests another way in which servers' tips can be affected by racial bias - to the extent that they are influenced by service ratings at all. It also calls into question the uncritical reliance on customer ratings of service workers' performance as a basis for compensation. ${ }^{179}$

In addition to being normatively ambiguous, tipping is structured in ways that facilitate the customer's reliance on social stereotypes, whether consciously or not, in making tipping decisions. At the same time, tipping provides servers with incentives to comply with customers' expectations or preferences, often in ways that conform to and confirm those stereotypes. The power difference that defines the customer-server relationship, along with the customer's authority to place a value on the server's performance, puts the customer in the position of the "perceiver" whose assessment will largely determine the outcome of their interaction, and the server in the position of both the "target" and the party to whom that outcome matters more. Further, and as we have seen, customers can use their tips to fulfill a number of social and psychological functions, and servers are motivated to maximize their tips by appealing to the customer's favor.

Because tipping is spontaneous and sensitive to situational factors, tipping decisions are susceptible to the influence of group-based biases and stereotypes, which, although invisible, are often powerful features of social situations. For example, to the extent that customers tip to show

177 See Lynn \& Sturman, supra note 155. Lynn and Sturman note that, while "little research" prior to their study examined customers' ratings of employee performance, "[s]upport for the existence of racial discrimination by consumers is strong ..., as is support for the existence of racial bias in peer and supervisory ratings of performance." Id. at 2314 (citations omitted).

178 The study's characterization of these dimensions of server performance as "situational" or "dispositional" was tested and confirmed by through a survey in which respondents indicated the degree to which they thought a server's performance was the "result of situational factors outside the server's control" as opposed to "personal characteristics of the server." Id. at 2316.

${ }^{179}$ See id. at 2317-19. 
their liking or empathy for the server, implicit biases might lead them to favor members of a particular racial group over others. The study by Lynn and his colleagues, of race effects on tipping, provides evidence of this potential, as do several studies suggesting that "consumers prefer members of their own race across many commercial contexts," for example, when choosing cashiers or responding to advertisements featuring same- versus different-race actors. ${ }^{180}$

Further, and whether or not they are conscious of acting on the opportunity, tipping provides customers with a means of enforcing stereotypical social preferences, because tips can be used to reward individuals who display stereotype-consistent characteristics or behavior or to express disapproval of those who do not. Studies have shown, in particular, that tipping behavior follows patterns that align closely with gender stereotypes. For example, consistent with the prescriptive stereotype that places a high value on physical beauty for women, studies have found that more attractive female servers received higher tips than less attractive waitresses ${ }^{181}$ and that waitresses' tips were higher when they wore flowers in their hair. ${ }^{182}$

Aside from a general societal preference for physically attractive women, one explanation for why better-looking female servers receive higher tips than less attractive female servers seems to be the way in which male customers, in particular, respond. Recent studies from France have found that male customers both rated female servers as more attractive and tipped significantly more when the servers wore facial cosmetics. ${ }^{183}$ Men also tipped significantly more when female servers wore red $t$-shirts than when they wore other colors. ${ }^{184}$ The tips of women customers, on the other hand, were not affected by these

${ }^{180}$ Lynn et al., Consumer Racial Discrimination in Tipping, supra note 25, at 1045 (citing studies reporting these and similar findings in a varicty of settings).

${ }^{181}$ See Michael Lynn, Determinants and Consequences of Female Attractiveness and Sexiness: Realistic Tests with Restaurant Waitresses, 38 ARCHIVES OF SEXUAL BeHAV. 737, 743 (2009); Lynn \& Simons, supra note 26.

${ }^{182}$ See Stillman \& Hensley, supra note 125, at 36; Michael Lynn \& Bibb Latané, The Psychology of Restaurant Tipping, 14 J. APPLIED SOC. PSYCHOL. 549,550 (1984).

${ }^{183}$ See Nicolas Guéguen \& Céline Jacob, Enhanced Female Attractiveness with Use of Cosmetics and Male Tipping Behavior in Restaurants, 62 J. CoSMETIC SCI. 283, 288 (2011) [hereinafter Guéguen \& Jacob, Enhanced Female Attractiveness]; Céline Jacob et al., Waitresses' Facial Cosmetics and Tipping: A Field Experiment, 29 INT'L J. HoSPITALITY MGMT. 188, 189 (2010).

${ }^{184}$ Nicolas Guéguen \& Céline Jacob, Clothing Color and Tipping: Gentlemen Patrons Give More Tips to Waitresses with Red Clothes, 20 J. HosprTALITY \& TOURISM RES. 1, 4 (2012) [hereinafter Guéguen \& Jacob, Clothing Color and Tipping]. 
factors. ${ }^{185}$ These findings suggest that male customers favor female servers whose appearance coincides with stereotypical gender preferences, because other studies have found that women are rated as being "more feminine," "healthier," "cleaner," "organized," and "popular," among other favorable qualities, when they wear facial makeup, ${ }^{186}$ and that "red increases the physical and sexual attractiveness of women" and influences "romantic attraction toward women." 187

For male servers, in contrast, tips do not seem to correlate with physical attractiveness, but instead to "service ability." 188 As the authors of a study of predictors of male versus female servers' average tip earnings described their findings, "physical attractiveness was a much better predictor of waitresses' average tips than of waiters' average tips"; "self-rated service was a much better predictor of waiters' average tips than of waitresses' average tips"; ${ }^{189}$ and, overall, "[among] the highest tipped employees were beautiful females [and] highly competent males." ${ }^{190}$ Notably, male servers also report "receiving a significantly higher percent tip ... than female servers." 191

Even the same behavior by waiters and waitresses might be rewarded differently depending on whether it is perceived as being gender appropriate. One study found that female servers received

${ }^{185} \mathrm{Id}$.

${ }^{186}$ See Guéguen \& Jacob, Enhanced Female Attractiveness, supra note 183, at 283-84 (citing studies).

${ }^{187}$ See Guéguen \& Jacob, Clothing Color and Tipping, supra note 184, at 2 (citing studies).

${ }^{188}$ See Lynn \& Simons, supra note 26 , at $244,246-47$ (reporting a study in which servers' physical attractiveness was rated by five male and five female judges, while their "service ability" was self-rated on three dimensions: attentiveness, speed, and knowledge).

${ }^{189} \mathrm{Id}$.

${ }^{190} I d$. at 250 . The other quality that correlated with higher tips was the ability to self-monitor, $i d$., that is, to be "sensitiv[e] and reactiv[e] to cues about the situational appropriateness of a person's own behavior," $i d$. at 243 . Women's relative inability to reap greater rewards for providing better service recalls the inability of black servers to receive higher tips for providing better, even "perfect" service in the Lynn et al. study discussed previously. See discussion supra notes 167-76.

191 Michael McCall \& Ann Lynn, Restaurant Servers 'Perceptions of Customers' Tipping Intentions, 28 INT'L J. HoSPITALITY MGMT. 594, 595 (2009) (reporting results of online survey of servers across the United States that received 1198 responses; noting, however, that this result "opens the door for further research examining the accuracy of these gender based impressions."). The reported gender difference in tips received might be attributable at least in part to the fact that diners tend to give higher tips at more expensive, upscale restaurants, which tend to have a higher proportion of male than female wait staff. See discussion infra notes 360-72. 
significantly higher tips when they drew a "smiley face" on the check, whereas male servers did not increase their tips and in fact received lower tips (though the difference was not statistically significant) when they did the same. The researchers speculated that customers viewed women's drawing of smiley faces as "normal"- - an expression of liking and friendliness"- but viewed a man who drew a smiley face as not friendly, but "strange." 192

That customers would respond differently to servers' appearance and behavior along gender lines is not surprising, for service work is often highly gendered. ${ }^{193}$ Restaurant service, in particular, has a history of both gender stratification and gendered service styles. ${ }^{194}$ Generally, waiting on tables has been defined as 'typical 'women's work' because women perform it and because the work activities are considered 'feminine."'195 At the same time, restaurant service has not been performed exclusively by women. Instead, positions as restaurant servers traditionally were segregated by gender, with each gender dominating in different types of restaurants and performing different styles of service. Men have traditionally staffed more prestigious, upscale restaurants (where, not incidentally, tips tend to be much higher) ${ }^{196}$ and performed more formal service that "requires servers to appear dignified and reserved and is gendered as masculine," while women have tended to work at middleand low-range "family style" restaurants and coffee shops, where "homestyle service promotes a casual, familial form of interaction and is gendered as feminine." 197 Over time, this "vertical segregation" has declined somewhat, although more prestigious restaurants continue to hire mostly male servers. ${ }^{198}$

Even within restaurants where male and female servers work side by side, the work itself continues to be defined in gendered terms. As one researcher found, "one form of table service is interpreted as waitering and the other is waitressing; waitering remains the higher status work." 199 Accordingly, in "low-prestige" restaurants, the mixed-gender staff are referred to as "waitresses," and the work-"to provide quick

192 Rind \& Bordia, supra note 87, at 218, 223; see also DuBlaniCA, supra note 72 , at 113 ("[I]f a guy draws a smiley face on the check, it's just plain creepy.").

${ }^{193}$ Erickson, supra note 120, at 549, 559 ("Service work, which requires deferring to others, entails emotional labor, relies on teamwork, and has traditionally been considered women's work.").

194 See generally Elaine J. Hall, Waitering/Waitressing: Engendering the Work of Table Servers, 7 GENDER \& SOC'Y 329, 342-43 (1993).

${ }^{195}$ Id. at 329.

${ }^{196}$ See infra note 359.

${ }^{197}$ Hall, supra note 194, at 330 (emphasis in original).

198 See infra notes 364-72.

${ }^{199}$ Hall, supra note 194 , at 331 . 
service in a busy restaurant where servers seat their own customers, fix their own desserts, and clean their own tables"-is "to waitress." 200 The work and job title in high-prestige restaurants, on the other hand, is that of "waiter." Accordingly, "to cater leisurely to customers in a formal restaurant where the staff stand waiting with their hands behind their back is 'to waiter"'--whether it is performed by a man or a woman. ${ }^{201}$

Servers who are motivated to increase their tips behave rationally when they play into customers' gendered expectations and preferences. For female servers this often means wearing cosmetics and stereotypically feminine or revealing clothing. As a group of waitresses explained to sociologist Elaine J. Hall, "dressing like a woman by wearing a skirt provided financial rewards. 'In a way it sounds sexist ... but I'd rather be in a skirt or dress because it brings better tips ... money, that's why I started waitressing." "'202 For some tipped servers, how they look is especially important because it does a kind of emotional labor. ${ }^{203}$ For a cocktail waitress at a casino, for example, the time to interact with customers is limited due to the customers' preoccupation with gambling, so the waitress "evoke[s] feelings in others chiefly through physical appearance." ${ }^{204}$ In such settings, female servers' uniforms tend to be especially revealing and their conformance to stereotypical standards of beauty (including those related to race, age, and weight) to be especially pronounced. ${ }^{205}$ And while some workers object to management's demands that they comply with sexist dress and grooming codes, ${ }^{206}$ many others "[take] pains to shape themselves into versions of ideal femininity" without "[o]vert management control,"207 because of their dependence on tip income. ${ }^{208}$

Pleasing the customer (and receiving bigger tips) often leads female servers to conform to gendered expectations and preferences about how they should interact with customers as well. One ethnographic study that focused on the emotional content of restaurant servers' interactions with customers found that men and women tended to adopt different strategies for "making sense of" and coping with the demands of their job. Men more often chose to "detach" or distance themselves emotionally from their customers, whereas women tended to "invest" or

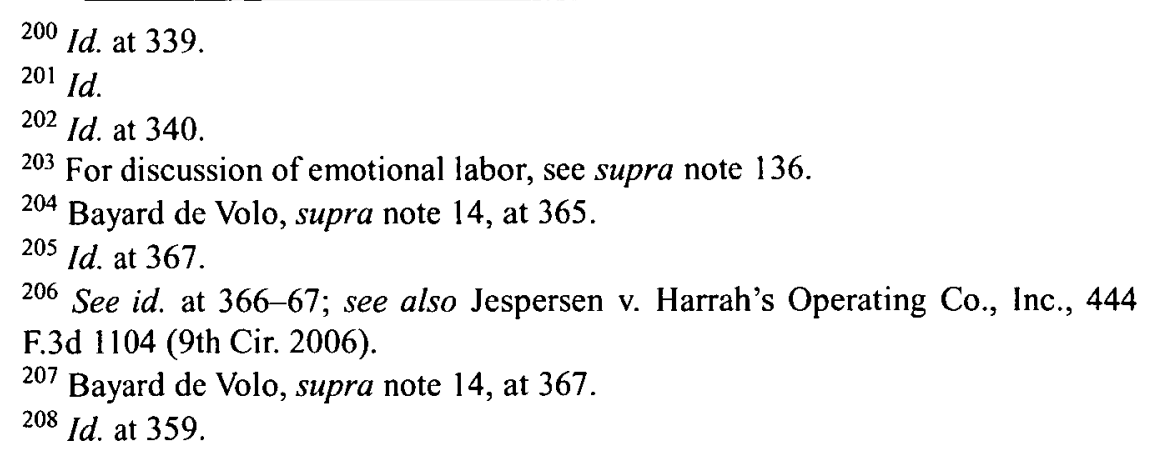


to adopt an "actually caring" strategy. ${ }^{209}$ The researcher noted that, not only did customers express a gendered preference for servers who showed stereotypically female concern and caring, but "because most women chose to invest, they unwittingly reinforce the assumption that women excel at nurturing and tending to others" 210 - thereby contributing to a self-fulfilling cycle of stereotype confirmation. ${ }^{211}$

\section{B. "SERVICE WITH A SMIRK":212 NORMATIVE AMBIGUITY IN RESTAURANT SERVICE}

Of course, stereotypes are not limited to customers' perceptions of workers. Servers also act on stereotypes of the other party, and in a transaction where the tip is the focal point, those stereotypes tend to center on that other party's expected behavior as a tipper and customer. ${ }^{213}$ Evidence abounds of restaurant servers' negative stereotypes of particular social groups as poor tippers. Those groups include women, older people, foreigners, teenagers, and "rednecks,"214 but perhaps the most widespread stereotype is of African-American customers, for race has become "a core issue in the interactions between restaurant workers and restaurant clientele." ${ }^{215}$ Servers themselves are open, if apologetic, about their dislike for serving African Americans, whom they view as poor tippers and demanding customers. In a study based on a series of interviews with restaurant workers, for example, the researchers reported that, "[i]n every one of the interviews, the shared sentiment and 'common knowledge' among white restaurant workers was that black Americans do not tip well and as such, servers should not 'waste their time' on these customers." ${ }^{16}$ One restaurant server stated that black customers "tend to be very snappy, and 'do this, do this', [sic] like 'ma'am,' snap in your face, and then don't leave you any tip, so most people don't want to serve them willingly." ${ }^{17}$ Similar views have

${ }^{209}$ See generally Erickson, supra note 120.

${ }^{210} I d$. at 567.

${ }^{211}$ Notably, however, and as will be discussed further below, the value that customers appear to place on a caring, nurturing, feminine style of "waitressing" does not necessarily translate into economic rewards. The higher status-and higher tipped-work of "waitering" still goes predominantly to men. See Hall, supra note 194, at 343.

${ }^{212}$ Dirks \& Rice, Dining While Black, supra note 107, at 271.

${ }^{213}$ See discussion supra Part 111 regarding servers' roles as experts and managers of the service encounter.

${ }^{214}$ See, e.g., McCall \& Lynn, supra note 191, at 594; Mallinson \& Brewster, "Blacks and Bubbas," supra note 102 (discussing stereotypes of "rednecks" as restaurant customers).

${ }^{215}$ Dirks \& Rice, Dining While Black, supra note 107, at 276.

${ }^{216} I d$. at 269.

${ }^{217} \mathrm{Id}$. 
been documented in other research studies and surveys, ${ }^{218}$ and aired in popular media and online discussions. ${ }^{219}$

In a 2004 study to "assess quantitatively the pervasiveness of restaurant servers' anti-Black perceptions (e.g., tipping and dining behaviors)," Zachary W. Brewster and Sarah E. Rusche conducted a survey of waiters and waitresses ( $86.2 \%$ of whom were white) at fullservice restaurants. ${ }^{220}$ Respondents "overwhelmingly" rated blacks their "least ideal" racial category of customers to serve. ${ }^{221}$ By way of explanation, a number of servers used harsh and inflammatory language to describe the tipping and dining behavior of black customers. Servers stated, for example, that "They tend to be demanding, unappreciative, and they DO NOT TIP!"; "They will try to make you feel like crap. They will try to get free food and do not tip."; and "[T]hey tip for shit!"222 Overall, respondents reported that they perceived white customers to be comparatively better tippers and easier to wait on than black customers. ${ }^{223}$ Their responses showed significant differences in the mean ratings of black and white customers, with mean ratings of black customers failing even to reach a rating of "average" and in some cases even falling lower than a rating of "below average." 224 Other surveys have produced similar results. ${ }^{225}$

${ }^{218}$ See Mallinson \& Brewster, "Blacks and Bubbas," supra note 102; Michael Lynn, Ethnic Differences in Tipping: A Matter of Familiarity with Tipping Norms, 45 CoRnell Hotel \& Restaurant ADMIN. Q. 12, 12 (2004) [hereinafter Lynn, Tipping Norms] (referring to an unpublished survey in which "94 percent of the servers classified black customers as poor tippers").

${ }^{219}$ See, e.g., Suzie Amer, Minority Report, RestauranT Bus., Nov. 15, 2002, at 26, available at 2002 WLNR 14668719 (quoting servers and comments on tipping.org).

${ }^{220}$ See Brewster \& Rusche, Quantitative Evidence, supra note 104, at 368-79; Sarah E. Rusche \& Zachary W. Brewster, 'Because they tip for shit!': The Social Psychology of Everyday Racism in Restaurants, 2 SOC. COMPASS 2008 (2008) [hereinafter Rusche \& Brewster, Racism in Restaurants].

${ }^{221}$ Rusche \& Brewster, Racism in Restaurants, supra note 220, at 2013 (noting that $54.6 \%$ of servers rated blacks "least ideal," while $2.6 \%$ rated them "ideal"; $64.7 \%$ rated whites "ideal" and $6.01 \%$ "least ideal").

222 Id. at 2014 (emphasis in original survey response).

${ }^{223}$ Brewster \& Rusche, Quantitative Evidence, supra note 104, at 372-73. The survey asked respondents to rate the tipping practices and dining behaviors of customers in matched pairs of a variety of scenarios (e.g., four women and two small children, two heterosexual couples, a family of eight with adult children), where the only factor that differed between matched pairs was the race of the patrons. Id. at 370 .

${ }^{224} I d$. at $372-73$. The mean ratings for white customers in the various scenarios, on the other hand, were average or higher except in the cases of the tipping practices of groups comprising white women (four white women with two small 
Servers also have been open about the effect of these stereotypes on the service they deliver. Through a series of interviews with restaurant workers, Danielle Dirks and Stephen K. Rice discovered a "culture of white servers" 226 in which the "backstage" interactions of "front of the house" workers-i.e., servers and hostesses, who tend to be white ${ }^{227}$ incorporate racist rituals and shape the service extended to people of color. This culture includes the use of private racial language and code words to refer to customers of color: "Canadians," "cousins," "moolies," and even "white people" were among the terms reportedly used by servers-but "only behind closed doors." 228 This private language not only degraded the customers to whom it referred, but also created a sense of "in-group solidarity" among the servers, thereby strengthening their backstage culture while at the same time "allow[ing] white servers to appear non-racist while still harboring negative racist sentiments." 229 When new servers joined the group, learning the racial code was "part of the informal employee "training." 230 Managers may also play a role in sustaining an anti-black culture, themselves adopting racial code words and making derogatory comments about black customers. ${ }^{231}$

According to the interviewees, servers regarded being assigned to wait on black customers as "punishment" that they tried to avoid.

children and four elderly white women) and the dining behavior of four white women with two small children. Id. at 373.

${ }^{225}$ See, e.g., Dirks \& Rice, Dining While Black, supra note 107, at 269 (reporting on interviews with restaurant workers who "[i]n every one of the interviews" conveyed the "common knowledge" that black customers do not tip well); Emily D. Noll \& Susan Arnold, Racial Differences in Restaurant Tipping: Evidence from the Field, 45 CORNELl HOTEL \& RESTAURANT ADMIN. Q. 23, 24-25 (2004) (reporting that, in a survey of ninety-nine restaurant servers who were asked to rate typical tip size by customer characteristics with 1 indicating below $15 \%, 2$ indicating about $15 \%$, and 3 indicating more than $15 \%$, the mean rating of the average tip from black customers was 1.25 and the mean rating of the average tip from white customers was 2.24). In Rusche and Brewster's survey, a high proportion of respondents reported that they observed coworkers stereotyping black customers "sometimes or often" (73.4\%) and some reported that they observed this "always" (13.5\%). Rusche \& Brewster, Racism in Restaurants, supra note 220, at 2015.

${ }^{226}$ Dirks \& Rice, Dining While Black, supra note 107, at 266.

${ }^{227}$ See, e.g., id. at 263-66 (discussing hiring and racial distribution of restaurant employees).

${ }^{228}$ Id. at 267-68; see also Rusche \& Brewster, Racism in Restaurants, supra note 220, at 2019 (noting "clever, though derogatory, terms" servers used to refer to tables with black customers, such as "black-tops," a play on "2-top" and "4-top").

${ }^{229}$ Dirks \& Rice, Dining While Black, supra note 107, at 268. ${ }^{230} \mathrm{Id}$.

${ }^{231}$ See Rusche \& Brewster, Racism in Restaurants, supra note 220, at 2017 (reporting survey results and examples). 
Hostesses bore the brunt of servers' avoidance tactics, which included telling the hostess not to assign them tables with black customers, and giving the hostess "eyes" and whispering, "Not in my section. Not in my section." when she seated black customers. If servers were assigned to a black table, they might also become angry with the hostess, asking her, "Do you hate me or [something?]"232 Sometimes fellow servers would attempt to "make deals" or "swap tables" to get out of waiting on black customers. ${ }^{233}$ Servers who ended up being assigned to tables with black customers, reported interviewees, often neglected those customers or delivered poor service. ${ }^{234}$

The 2004 survey also measured the prevalence of such conduct. ${ }^{235}$ Survey respondents reported "moderately common"236 racist behavior among workers and managers. Specifically, they reported hearing racist comments by coworkers ${ }^{237}$ and managers, ${ }^{238}$ the use of code words to refer to customers, ${ }^{239}$ and servers' discussing the race of customers with one another. ${ }^{240}$ Many respondents reported that they themselves varied the service they provided according to the customers' race $^{241}$ and observed coworkers doing the same ${ }^{242}$-specifically, treating black patrons poorly. ${ }^{243}$ The researchers conservatively estimated that "roughly

232 Dirks \& Rice, Dining While Black, supra note 107, at 269-70.

${ }^{233}$ Id. at 271.

${ }^{234}$ Id . at $271-72$.

${ }^{235}$ The researchers noted, however, that their "survey data do not permit [them] to speak to the type of stereotyping, poor treatment, and racist discourse that respondents report observing." Rusche \& Brewster, Racism in Restaurants, supra note 220 , at 2024 (emphasis in original). Their related field study, however, did provide data of that kind. Id.

${ }^{236}$ Brewster \& Rusche, Quantitative Evidence, supra note 104, at 377.

${ }^{237}$ Id. at 374 (46.1\% "sometimes," 13.6\% "often," and 3.7\% "always").

${ }^{238}$ Id. (22.4\% sometimes, $2.6 \%$ often, and $1 \%$ always).

${ }^{239} \mathrm{Id}$. (38.1\% sometimes, $22.7 \%$ often, and $8.8 \%$ always).

${ }^{240} \mathrm{Id}$. at 372,374 (59.0\% sometimes, $14.9 \%$ often, and $1.5 \%$ always); see also Rusche \& Brewster, Racism in Restaurants, supra note 220, at 2015. Note that these reports focus on a common feature of "racial language as private discourse": "individuals frequently make derogatory and stereotypical remarks about black Americans through shared 'backstage' or private discourse among other white Americans." Dirks \& Rice, Dining While Black, supra note 107, at 260.

${ }^{241}$ Brewster \& Rusche, Quantitative Evidence, supra note 104, at 374 (31.8\% sometimes, $4.6 \%$ often, and $2.1 \%$ always).

${ }^{242}$ Id. (54.4\% sometimes, $9.7 \%$ often, and $1.5 \%$ always).

${ }^{243} \mathrm{Id}$. (38.7\% sometimes, $8.9 \%$ often, and $5.2 \%$ always). The researchers speculated that respondents may have understated their self-reports of discrimination due to the tendency of individuals to respond to sensitive questions in ways that they perceive to be socially desirable: "It is thus likely that some observed discrimination is in reality self-reported discrimination that 
2 meals out of every 50 meals served in the average sampled restaurant results in an incident of discriminatory service"-adding up to about "7,018 annual incidents of discriminatory service delivery per sampled restaurant."244

That race discrimination in restaurant service is so common may be hard to believe at a time when the ideal of racial equality seems to be well-accepted and federal and state laws prohibit race discrimination in public accommodations such as restaurants. ${ }^{245}$ But in fact, it is quite possible for racially discriminatory service to be delivered on a regular basis without its being clear or obvious, because the quality of serviceas well as the reasons why different levels of service might be provided to different customers-is highly ambiguous. In other words, both of the kinds of normative ambiguity that promote and obscure discrimination characterize this side of the customer-server interaction as well. ${ }^{246}$

Without a doubt, discrimination in restaurants and other public accommodations often takes blatant and undeniable forms, and in some cases has resulted in high profile litigation and multi-million dollar settlements. ${ }^{247}$ Refusals to seat black customers, seating or serving black customers after whites who arrived later, and imposing a "service charge" on black customers that is not imposed on whites are just a few examples of mistreatment that have been reported. ${ }^{248}$ In many-perhaps most-cases, however, discriminatory service may be "subtle and difficult to detect" because of a divergence between "backstage" maneuvering and workers' "frontstage" conduct, which is "governed by

respondents are projecting onto their coworkers." Id. at 376. See also Rusche \& Brewster, Racism in Restaurants, supra note 220, at 2016-18.

244 Brewster \& Rusche, Quantitative Evidence, supra note 104, at 377 (basing their calculation on an estimated " 171,168 meals served per year in the average restaurant that participated in [their] study").

${ }^{245}$ See, e.g., 42 U.S.C. $\$ 2000$ a (2006).

246 See supra notes $150-51$.

${ }^{247}$ See, e.g., Edward Iwata, Restaurant to Settle 7 Lawsuits, Pay $\$ 8.7$ Million, USA TODAY, Sept. 9, 2004, http://usatoday30.usatoday.com/money/industries/fo od/2004-09-09-cracker-barrel_x.htm\# (reporting on restaurant chain's settlement of lawsuits alleging it discriminated against black customers and workers, including by denying service to black customers); Stephen Labaton, Denny's Restaurants to Pay $\$ 54$ Million in Race Bias Suits, N.Y. TIMES, May 25, 1994, http://www.nytimes.com/1994/05/25/us/denny-s-restaurants-to-pay54-million-in-race-bias-suits.html?pagewanted=all\&src=pm (reporting on restaurant chain's settlement of "lawsuits filed by thousands of black customers who had been refused service or had been forced to wait longer or pay more than white customers").

${ }^{248}$ See, e.g., Lynn \& Thomas-Haysbert, supra note 31, at 1747; Siegelman, supra note 28 , at $83-84$. 
acceptable modes of behavior." ${ }^{249}$ Even servers who dislike waiting on customers of color are less likely to provide blatantly discriminatory service than they are to deliver what Dirks and Rice have called "service with a smirk" ${ }^{250}$ exerting minimal effort, doing only what they have to do, and not "go[ing] out of their way to be friendly."251 "Service with a smirk" takes the form of bare-bones service delivery without the value adding, rapport building, socially immediate, sometimes "over the top" attentiveness and emotional labor that servers are motivated to perform when they perceive it as being in their self-interest to do so. ${ }^{252}$ Service that lacks these qualities is normatively ambiguous: It might not be clearly substandard and might even be quite effective in a technical sense. ${ }^{253}$ At the same time, such minimal, lackluster service fails to make customers feel welcome and cared for and

undoubtedly has adverse effects on the dining experiences of African American customers even if they are not cognizant of such treatment as constituting discrimination.... [W] hile such forms of discrimination may not be reported in victimization surveys, they do nevertheless constitute ways servers can differentially deliver hospitability according to the race of their customers. $^{254}$

Put differently, this type of discriminatory service indicates that blacks are "seen by white servers as undeserving of enjoyable dining experiences." 255

On the other hand, even servers who acknowledge providing a lower level of service to black customers might not equate their reduced service with race discrimination, because they see it as engaging in normal, tip-focused "credit selection." 256 That is, they are doing simply what rational, self-interested tipped workers commonly and understandably do-follow the "self-fulfilling prophecy" strategy in which "a prediction of a large tip [leads] to increased service effort and

249 Dirks \& Rice, Dining While Black, supra note 107, at 276.

${ }^{250}$ Id. at 271 .

${ }^{251} \mathrm{Id}$.

${ }^{252}$ See, e.g., Brewster \& Mallinson, supra note 113, at 1061-63; Brewster \& Rusche, Quantitative Evidence, supra note 104, at 366-67. See discussion of "value added service" and emotional labor supra Part III.

${ }^{253}$ Cf. Brewster \& Mallinson, supra note 113, at 1058.

${ }^{254}$ Brewster \& Rusche, Quantitative Evidence, supra note 104, at 367.

${ }^{255}$ Rusche \& Brewster, Racism in Restaurants, supra note 220, at 2026.

${ }^{256}$ See discussion supra Part III. 
[a] prediction of small tips [leads] to decreased service effort." 257 Indeed, servers in this situation may feel that they are the ones aggrieved in an unfair exchange, seeing themselves as victims of "exploitative customers." ${ }^{258}$ Of their interviews with restaurant servers, Mallinson and Brewster observed that, "when derogating black patrons, servers tend[ed] to formulate a standpoint-based statement against them and support[ed] these opinions with arguments based specifically on narrow economic grounds."259 Servers' predictions regarding the tipping behavior of black customers thus provide a non-racial justification for "decreased service effort," clouding the situation with normative ambiguity ${ }^{260}$ At the same time, servers also might "draw on their preexisting stereotypes [of certain groups as poor tippers] to rationalize [their] unsuccessful interaction," to avoid attributing their low tips to the server's own poor performance. ${ }^{261}$

Perhaps not surprisingly, servers' accounts of their views and treatment of black customers often are "peppered with disclaimers and mitigators," 262 frequently of the "I am not a racist, but ..." variety. ${ }^{263}$ Likewise, and perhaps in an attempt to appear non-racist or to enhance their credibility, white servers commonly point out that their black coworkers say the same things about black customers. ${ }^{264}$ Further, some servers seem to be genuinely upset to find themselves approaching black customers differently from customers of other races based on their need or desire for bigger tips. Emily D. Noll, whose experience as a restaurant server prompted her to conduct her own research study of racial differences in restaurant tipping, writes candidly of feeling both "distressed over the environment of crude language and attitudes of [her] fellow servers toward black customers" and "frustrated with [her] black customers," who she had found would "usually (and predictably) tip [her] less than 15 percent." 265 Even as Noll "went on providing the best

${ }^{257}$ Barkan \& Israeli, supra note 94, at 96 (discussing restaurant servers' roles as "experts and managers of tipping behaviour"); see discussion supra Part III.

${ }^{258}$ Mallinson \& Brewster, "Blacks and Bubbas," supra note 102, at 796.

259 Id. at 798.

${ }^{260}$ See Brewster, supra note 103, at 23 (situating the statistical discrimination explanation within "the contemporary racial ideology of colorblindness" and identifying it as "a common discursive move utilized by whites to explain away racial disparities in a color-blind fashion").

${ }^{261}$ Mallinson \& Brewster, "Blacks and Bubbas," supra note 102, at 802.

${ }^{262} \mathrm{Id}$. at 795.

${ }^{263}$ See, e.g., Dirks \& Rice, Dining While Black, supra note 107, at 259-60; Mallinson \& Brewster, "Blacks and Bubbas," supra note 102, at 789, 796.

${ }^{264}$ See, e.g., Mallinson \& Brewster, "Blacks and Bubbas," supra note 102, at 795.

${ }^{265}$ Emily D. Noll \& Susan Arnold, Racial Differences in Restaurant Tipping: Evidence from the Field, 45 CORNELL HOTEL \& RESTAURANT ADMIN. Q. 23, 27 (2004) (discussing "A Personal Note" by Noll). 
service possible to all customers," she reports that she "found [herself], too, badgering the hostess to please give [her] the 'tipping customers': After all, [she] did have to buy overpriced college textbooks." 266

Still, some servers who treat customers of different races differently might not be aware that they do. Dirks and Rice's interviews with restaurant workers highlight this point. They observed that, while reporting on and "essentially demoniz[ing]" coworkers' discriminatory conduct, many respondents initially stated that "they always gave equal service to everyone, and most reported that they had not experienced tipping differences at all"- -until later in the interviews, that is, after "respondents began to delve more deeply into their own personal attitudes and actions and began to share them."267 At that point and with reluctance, some of the interviewees offered accounts of their own arguably discriminatory behavior towards black customers. ${ }^{268}$

In fact, statistics support at least one of the justifications servers assert for lowering their service effort with black customers. Studies have found that members of different racial and other social groups generally $d o$ tip at different levels, ${ }^{269}$ and in particular that black customers tend to give smaller tips, as well as to "stiff" (give no tip) more frequently, than do whites. ${ }^{270}$ On the other hand, no empirical

${ }^{266} \mathrm{Id}$.

${ }^{267}$ Dirks \& Rice, Dining While Black, supra note 107, at 274.

${ }^{268}$ Id. at $274-75$.

${ }^{269}$ For example, Jews and individuals with no religious affiliation have been found to be especially generous tippers compared to Christians, who themselves tend to tip within the $15 \%-20 \%$ norm despite being stereotyped as poor tippers. See Lynn \& Katz, supra note 100 . Asians have been found to tip comparably to whites, see Michael Lynn, A Comparison of Asians', Hispanics' and Whites' Restaurant Tipping, 43 J. APPLIED SOC. PSYCHOL. 834 (2013) [hereinafter Lynn, A Comparison]; Lynn \& Thomas-Haysbert, supra note 31 , while studies have found both that Hispanics tip less than and that they tip comparably to whites, see Lynn, A Comparison, supra; Michael Lynn, The Contribution of Norm Familiarity to Race Differences in Tipping Behavior: A Replication and Extension, J. HOSPITALITY \& TOURISM RES. (forthcoming 2014) [hereinafter Lynn, Contribution of Norm Familiarity].

${ }^{270}$ See, e.g., Ayres et al., supra note 19, at 1628-29; Lynn \& Thomas-Haysbert, supra note 31; Michael Lynn, Black-White Differences in Tipping of Various Service Providers, 34 J. APPLIED SOC. PSYCHOL. 2261, 2264-65 (2004); Leodoro \& Lynn, supra note 128, at 201, 204-05; Noll \& Arnold, supra note 265 , at 26-27 (reporting on study of small sample, 151 parties, finding that $46 \%$ of all-black parties and $18 \%$ of all-white parties tipped less than $15 \%$ and that the mean percentage tipped by black parties was $11.97 \%$ and for white parties was $16.84 \%$ ). 
evidence substantiates the stereotype that black customers are more difficult to serve than other customers. ${ }^{271}$

But, as the next section discusses, inferior service to customers of color should not be understood as a simple case of "statistical" (so-called "rational" or "colorblind") discrimination. Servers' expectations of black customers' tipping and dining behavior provide only a partial explanation for racial disparities in service quality. Servers' stereotypes and treatment of black customers differ from their stereotypes of other groups that are commonly viewed as poor tippers in ways that reflect more than simply rational, self-interested calculation. Furthermore, the tipping practices of black customers on which servers' stereotypes focus are themselves at least partly a consequence of black customers' longstanding experience and expectation of receiving inferior service- $-\mathbf{a}$ product of a self-fulfilling prophecy of discrimination.

\section{C. "A MUTUALLY REINFORCING, UNHAPPY EQUILIBRIUM"272}

According to a recent study, servers do appear to engage in statistical discrimination against black customers. ${ }^{273}$ The study found that servers who expressed more positive views of African-American customers' tipping and dining practices were less likely to report that they discriminated in service delivery, while those who reported holding negative stereotypes were more likely to report discriminating. These findings suggest that the racial stereotypes held by servers provide an economic motivation "to statistically discriminate in . . . service delivery." 274 On the other hand, while this analysis found support for the "statistical discrimination framework," it also found that "the framework's explanatory utility is limited," because servers" "perceptions of blacks' tipping practices (revenue-based inferences) and dining behaviors (cost-based inferences) are only able to explain roughly $4.1 \%$ and $2.5 \%$, respectively, of the overall variation [in service delivery]... . [O]ther factors . . . are clearly implicated in the disparate treatment that African Americans continue to encounter in full-service restaurants." 275

271 See Brewster \& Rusche, Quantitative Evidence, supra note 104, at 378.

${ }^{272}$ Ayres et. al., supra note 19 , at 1651 .

${ }^{273}$ Brewster, supra note 103, at 22 (providing a separate analysis of the 2004 restaurant server survey data examined in Brewster \& Rusche, Quantitative Evidence, supra note 104, that the researcher described as "the first quantitative assessment of the commonly assumed relationship between perceptions of blacks' tipping practices and discriminatory service delivery" and of "the effects of servers' perceptions of blacks' dining behavior on servers' propensity to discriminate").

274 See Brewster, supra note 103, at 22-23.

275 Id. at 23. 
Closer examination of the views that servers express concerning black customers reveals some of those "other factors"-particularly when those views are studied alongside servers' stereotypes of others whom they consider to be poor tippers and bad customers. In a recent, interview-based study, Christine Mallinson and Zachary W. Brewster compared restaurant servers' discourse about two groups whom the servers regarded as undesirable customers: African Americans and "redneck" native white Southerners. ${ }^{276}$ The researchers found some similarities in servers' derogatory discourse about both groups-one a racist discourse and the other a discourse of "linguistic prejudice,"277 but both rooted in "ideologies of racial superiority." 278 In particular, servers employed what the researchers call "standpoint-based" argumentation in discussing both groups of customers. In this style of argument, the speaker presents evidence for both a negative view of the other and a positive view of the speaker. ${ }^{279}$ When discussing black patrons, for example, the subjects' standpoint-based arguments would focus on "narrow economic grounds" and

employ tactics such as telling stories, citing numbers, and claiming reversal to support their assertions about blacks' poor tipping practices and their own economic disadvantage, and to construct their own credibility as witnesses to these actions. At the same time, they heavily mitigate their statements, especially with familiar disclaimers, as being general behavioral 'rules' or tendencies that may have exceptions, again engaging in credibility-enhancing moves. ${ }^{280}$

These rhetorical strategies are evident in the interviews conducted by other researchers and discussed above in connection with servers' asserted statistical justifications for providing low service effort to black customers. ${ }^{281}$ An example of a server making a standpoint-based

${ }^{276}$ Mallinson \& Brewster, "Blacks and Bubbas," supra note 102, at 791. The researchers originally set out to study servers' racist discourse but found that interview subjects engaged in discussions about rednecks as undesirable patrons that were similar to their talk about black patrons. Id.

${ }^{277}$ Id. at 789 (explaining that linguistic or "dialect" prejudice "against those who speak nonstandard varieties of English" is "rampant" and "[o]ne of the most heavily stigmatized nonstandard social dialects, not only historically but also in contemporary America, is Southern vernacular English.").

${ }^{278}$ Id. at 789-90, 800-01 (explaining that the ideology of racial (i.e., white) superiority shares roots with ideologies of regional and class identity that stigmatize both of these groups of patrons).

279 See id. at 791.

280 Id. at 798.

281 See discussion supra Part IV.B. 
statement about redneck customers that employs some of these tactics can be found in the interview of a server named Samantha:

Interviewer: Are there any tables that you think of as bad tippers?

Samantha: (laugh) yeah.

Interviewer: What type of tables are those?

Samantha: Umm, it's kinda bad to say but the ones that come straight out of the trailer park and they come in and they want, they ask if you have Busch Light in a can (laugh). And then you gotta worry. You know if they ask if you have hush puppies, and then you wonder if they know they're at [restaurant name] or if they think they're at [restaurant name]. You know and those people that, you can tell when people don't go out to eat very often, you can tell by the way they act and by the way they eat. Their cleanliness while they are eating. And that's when you're like please don't give me that table. ${ }^{282}$

On the other hand, two notable differences emerged between servers' discourse about black customers versus redneck customers, as illustrated by Samantha's interview. First, Mallinson and Brewster observed that subjects more frequently engaged in positive self-presentation-using disclaimers or euphemisms to mitigate their negative statements about the group in question, for example - when discussing black patrons, as opposed to rednecks. ${ }^{283}$ With regard to redneck customers, subjects were more overtly—even "strikingly"284_-denigrating: They supported their negative descriptions with "more opinions and stereotypes than particular "facts" and "engage[d] in more direct and often morally evaluative otherizing talk that draws on these stereotypes and essentializes the redneck personality and/or culture."285 The researchers speculated that subjects may have felt freer to speak negatively about

${ }^{282}$ Mallinson \& Brewster, "Blacks and Bubbas," supra note 102, at 797 (noting in particular that, just as another subject did in speaking about black patrons, "Samantha presents herself positively as someone who speaks the truth in her characterizations of rednecks and/or is not afraid to appear politically incorrect, at least to the interviewer. Her standpoint-based argument that rednecks are bad tippers also includes several disclaimers, hesitation, and a diminutive ('kinda'), which functions as a 'shock absorber' that mutes a speaker's position and makes it seem less dramatic.").

${ }^{283}$ See id. at 799.

${ }^{284} \mathrm{Id}$. at 800 .

${ }^{285}$ Id. at 798 . 
rednecks because, in contrast to engaging in racist discourse, "it is not yet considered un-"politically correct"' to do so. ${ }^{286}$

At the same time, however, a second difference revealed servers' views about the rednecks to be more particularized and about the blacks to be more categorical. The researchers observed that, when talking about redneck customers, the servers "employ[ed] a multidimensional process of stereotyping based on a panoply of essentialized regional and/or class-related differences." ${ }^{287}$ Servers noted, for example, redneck customers' "linguistic behavior, table manners, and style of dress," 288 as well as their food and drink preferences and probable lack of familiarity with eating out. ${ }^{289}$ These somewhat elaborate portrayals recall the cab drivers' typology of customers discussed above that included features such as the customers' occupation, personality, social class, and occasion for using the service. ${ }^{290}$

In contrast, when talking about black customers, servers engaged "in a more or less one-dimensional process based on the single characteristic of race."291 Rather than "distinguish among different types of black patrons . . . merely assessing their race seem[ed] enough to invoke a gamut of cultural stereotypes (such as stinginess or even poverty) that correspond[ed] with the cognitive category of 'black' in [the servers'] minds." ${ }^{292}$ As one server in a separate study flatly declared, for example, "Blacks and Hispanics don't tip above $\$ 3.00$ no matter how large the bill." 293 While noting a tendency to "lump people into categories," the authors of that study observed: "Not only did this server generalize behavior of two racial/ethnic groups, but also associate[d] customers' race with a concrete dollar amount." 294

In addition to portraying black customers as a homogeneous group, servers' stereotypes reflect historical stereotypes of blacks as "uncivilized and hedonistic." 295 The stereotype of blacks as difficult, demanding, and rude customers-which, again, has not been substantiated empirically - conjures that racist image and serves to rationalize unequal treatment. Quoting noted sociologist Joe Feagin, Brewster and Rusche explain:

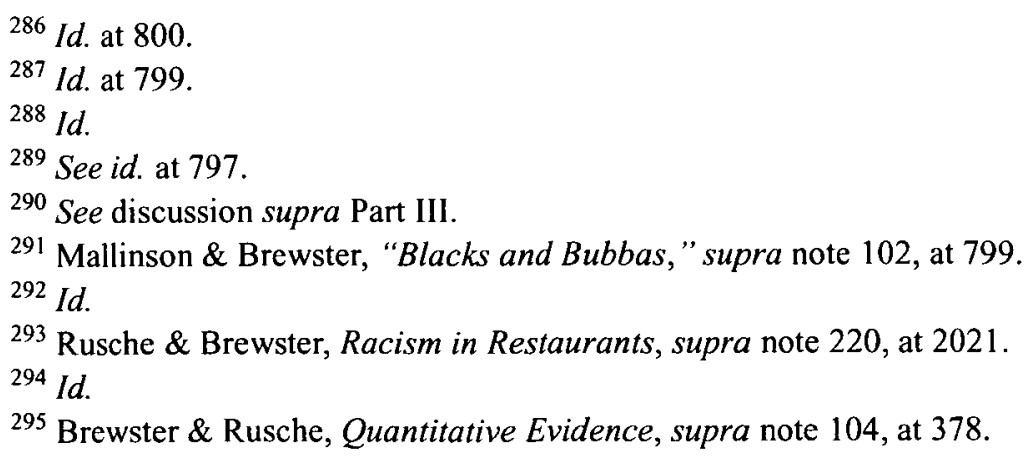


"[F]or centuries, this white frame has operated to hide or disguise the injustice of oppression by insisting, among other things, that oppressed groups are in various ways 'not like us,' but instead are culturally, socially, and racially inferior." In this way, servers may potentially rationalize giving inferior service to Blacks because, unlike themselves, Blacks are uncivilized in their dining behavior, and as such, inferior service is warranted. ${ }^{296}$

Indeed, the reasons why black customers may be inclined to tip poorly, sometimes even stiffing servers, are closely tied to their experiences and anticipation of discrimination in restaurants, as well as their experiences with and perspectives on the practice of tipping itself.

No single explanation accounts fully for the documented tendency of blacks to undertip compared to other groups. One likely, though only partial, explanation is that African Americans are generally less "familiar[] with or commit[ted] to" 297 the norm of tipping $15-20 \%$ of a restaurant bill. Michael Lynn has examined this potential explanation through extensive studies that included surveys, self-reports, and observational data. Among his key findings are that blacks are significantly less likely than whites to report awareness of, or to tip in accordance with, this norm. In particular, blacks are significantly more likely than whites to view a flat dollar amount as an appropriate tip in contrast to a percentage of the bill size, as well as to consider a tip of less than $15 \%$ of the bill to be appropriate. ${ }^{298}$ This race difference in awareness of the norm does not appear to be related to socio-economic status. ${ }^{299}$ Lynn also has found that Hispanics are significantly less aware

${ }^{296}$ Id. (quoting JOE FEAGIN, SYSTEMIC RACISM: A THEORY OF OPPRESSION (2006)) (citations omitted).

${ }^{297}$ Lynn \& Thomas-Haysbert, supra note 31, at 1767.

${ }^{298}$ See, e.g., id.; Lynn, Tipping Norms, supra note 218; Michael Lynn, Geodemographic Differences in Knowledge About the Restaurant Tipping Norm, 36 J. APPLIED SOC. PSYCHOL. 740 (2006) [hereinafter Lynn, Geodemographic Differences]; Michael Lynn, Race Differences in Tipping: Testing the Role of Norm Familiarity, 52 CORNELL HOSPITALITY Q. 73 (2011) [hereinafter Lynn, Testing the Role of Norm Familiarity]; Lynn, Contribution of Norm Familiarity, supra note 269.

${ }^{299}$ See Michael Lynn \& Jerome Williams, Black-White Differences in Beliefs About the U.S. Restaurant Tipping Norm: Moderated by Socio-economic Status?, 31 INT'L J. HospitaliTY MGMT. 1033 (2012). More specifically, "black-white differences in awareness that it is customary to tip a percentage of the bill declined as socio-economic status increased," but "black-white differences in awareness that [it] is customary to tip 15-20 percent in restaurants were unrelated to socio-economic status." Id. at 1034-35. 
than whites of the restaurant-tipping norm. ${ }^{300}$ Lynn has pointed out that black-white differences in tipping contribute to several problems for both black customers and the restaurant industry, including servers' dislike of waiting on - and consequent delivery of inferior service toblack customers, management's difficulty in recruiting and retaining wait staff in predominantly black neighborhoods, and restaurant corporations' resultant reluctance to locate full-service restaurants in those areas. ${ }^{301}$

Even while emphasizing the existence and importance of this awareness gap, Lynn is careful to note that it is just a partial explanation for black-white differences in tipping behavior. Specifically, Lynn estimates that even "completely eliminating race differences in awareness of the $15 \%$ to $20 \%$ restaurant tipping norm will likely reduce Black-White differences in restaurant tip percentages by only about $30 \%$." 302

In addition to being less aware of the particulars of tipping, AfricanAmerican customers may be less "committed to" the norm of tipping generally because of the uneasy history of race and tipped positions. When tipping first took hold in the United States during the late nineteenth and early twentieth centuries, many Americans regarded taking tips as the mark of an inferior, servile person who neither possessed self-respect nor deserved their respect. ${ }^{303}$ This view often was expressed in racist terms, with some commentators openly associating tip-taking with inferiority and African Americans. One journalist, for example, wrote that "one expects" African American "servants" to take tips: "[I]t is a token of their inferiority. But to give money to a white man was embarrassing to me.... Tips go with servility, and no man who is a voter in this country by birthright is in the least justified in being in service." ${ }^{304}$ In fact, African-American workers depended more on tips than did their white counterparts. A 1903 survey, for example, found that "restaurants invariably pay less wages to colored waiters than they pay to white ones," 305 with black waiters earning on average a salary of " $\$ 18$

${ }^{300}$ See Lynn, Geodemographic Differences, supra note 298; Lynn, Contribution of Norm Familiarity, supra note 269.

${ }^{301}$ Lynn, Testing the Role of Norm Familiarity, supra note 298, at 73.

${ }^{302}$ Lynn, Contribution of Norm Familiarity, supra note 269 (manuscript at 10) (available online). Lynn also estimates that completely eliminating the Hispanic-White difference in awareness "will likely reduce Hispanic-White difference in restaurant tip percentages by only about $10 \%$." Id.

${ }^{303}$ See SEGRAVE, supra note 15 , at 10.

${ }^{304}$ Id. at 10-11 (quoting JOHN GILMER SPEED, TIPS AND COMMISSIONS 748 (1902)).

${ }^{305}$ SEgrave, supra note 15, at 11 (quoting James Samuel Stemons, Tippingthe Other Side, 55 INDEPENDENT 726-27 (Mar. 26, 1903)). 
to $\$ 22$ per month including tips, while white waiters averaged $\$ 30$ to $\$ 35$ per month." 306

Some employers - most prominently the Pullman railroad company-used both the tipping system and the stereotype of African Americans as subservient and inferior to their economic advantage, by paying their porters (all of whom were black) low wages, making that fact widely known, and playing upon the sympathies of passengers to make up for the employer's deficiency with tips. ${ }^{307}$ The porters suffered under this arrangement, which made them dependent on "the largesse of the mostly white passengers." 308 In fact, one of the first acts the Pullman porters undertook when they organized into the Brotherhood of Sleeping Car Porters in 1925 was to petition the Interstate Commerce Commission (ICC) for an order prohibiting tips. Their petition explained: "Only Negroes, many of them ex-slaves, were employed as porters. This caused the work to be looked on as menial and servile and led to the giving and taking of gratuities." ${ }^{" 309}$ In reviewing these events, Ayres, Vars, and Zakariya commented:

That porters would ask the ICC to prohibit a form of their compensation is remarkable. True, a tipping prohibition would put pressure on the Pullman Company to pay higher wages. But it is hard to imagine that the increase in wages would more than offset the loss of tipping income. The petition may therefore have had a noneconomic motive. Even if the prohibition would not increase their net incomes, the black porters' union might have wanted it nonetheless-possibly to increase the dignitary dimensions of their employment. They too may have seen the receiving of tips as "a token of their inferiority" and wanted to move away from an equilibrium of having to scrape and bow for their living. ${ }^{310}$

With this history, perhaps it is no wonder that some members of racial minority groups, particularly African Americans, might be especially sensitive to the stereotype that "jobs where employees are tipped somehow are not 'real jobs." "311 Couple that perspective with the fact that, for much of this nation's history, blacks could serve whites at

\footnotetext{
306 SEGRAVE, supra note 15 , at 11 .

${ }^{307} \mathrm{Id}$. at $17-18$.

308 Id. at 51 .

${ }^{309} \mathrm{Id}$.

${ }^{310}$ Ayres et al., supra note 19, at 1622-23 (footnotes omitted).

311 Gerald A. Fernandez, The Tipping Point-Gratuities, Culture, and Politics, 45 Cornell Hotel \& Restaurant Admin. Q. 48, 49 (2004).
} 
hotels and restaurants but not patronize those same businesses themselves, and it is not hard to understand why, as one hospitality industry executive explains, "[f]or many African Americans, a resentment still exists against the white establishment that denied black people basic human rights such as eating a meal in a public place. This resentment contributes to the way blacks may think about tipping." 312

It may be the case, as well, that African-American and other minority group customers are not, in fact, generally worse tippers than others, but instead tip differently for different levels (and kinds) of service. As Ayres and his co-authors suggest in their study of the tipping of cab drivers, "it may just be that passengers of all races tend to tip less for poor service and that drivers disproportionately give poor service to minority passengers." ${ }^{313}$ Ayres et al. further note that the immediate service might not be the only basis on which a customer determines the tip: "For example, minority passengers might tip less because (1) the current driver, (2) a prior driver, or (3) a prior retailer provided poorer service to the minority passengers (or their families or friends)." 314

As we have seen, restaurant servers both informally and in studies have admitted that they provide, and have observed their colleagues providing, inferior service to customers of color-"service with a smirk"-based on the expectation that those customers are poor tippers. ${ }^{315}$ That lower level service tends to lack the personalized touches that have been found to lead to larger tips ${ }^{316}$ and could provide a distinct reason why customers from some groups tend to tip less than others.

Certainly, some restaurant servers recognize that stereotypes regarding customers' tipping habits can set in motion a self-fulfilling cycle by affecting the service they provide, and in turn, the tips they receive from those customers. As one server stated, "Many servers in this restaurant will say things like 'I'm not waiting on that table (of black people); they won't tip!' Their service and tips in turn reflect this attitude. ${ }^{\prime 317}$ Another server described her coworkers' approach to serving

312 Id

${ }^{313}$ Ayres et al., supra note 19 , at 1650.

314 Id.; see also Brewster \& Mallinson, supra note 113, at 1064 (arguing that "certain social groups are less committed to the $15-20 \%$ [restaurant] tipping norm because they receive minimal or 'secondary' service over time and as a group, from servers.").

315 See discussion supra Part IV.B.

316 See discussion supra Part III.

${ }^{317}$ Rusche \& Brewster, Racism in Restaurants, supra note 220, at 2017. Another server in the same study stated, "I have seen lots of servers, who, like me, get these generalizations in their head, they start to believe in it and then they act on them, treat people like shit because of that fact, and I'm like, well maybe you've missed a couple of really good tips because of that." Id. at 2018. 
black customers by asking, "why give someone good service to try to prove you wrong [that black diners do not tip well] when it's so much easier to have them prove you right?"318

Whatever their source, stereotypes and biases on both sides of a tipping transaction can interact in mutually reinforcing ways to set up a self-fulfilling prophecy of economic discrimination. As Ian Ayres and his co-authors have stated, it may be that

minority passengers and drivers are caught in a mutually reinforcing, unhappy equilibrium in which minority passengers give little because they are generally exposed to poor retail treatment, while drivers generally provide poor treatment because they expect a poor tip. ${ }^{319}$

Collectively, these expectations and interactions form the background against which future transactions occur. As Dirks and Rice explained in their analysis of white restaurant server culture:

Poor tips become a confirmation of the servers' personal beliefs and contribute to the shared organizational knowledge. The cycle is perpetuated when existing servers' perceptions of their experiences generate a discourse that helps to shape incoming employees' belief structures. ${ }^{320}$

The reciprocal, reinforcing cycle by which customers' and servers' expectations interact resembles the process described above by which self-fulfilling, stereotypical expectations affect servers and their tips. ${ }^{321}$ It is not hard to see how these dynamics can result in unequal economic outcomes on both sides of tipped transactions - outcomes that, as the next Part discusses, are generally not remediable through legal claims.

\section{IMPLICATIONS OF THE "TRIANGULAR RELATIONSHIP": 322 TOWARDS A STRUCTURAL APPROACH TO REFORM}

Despite the existence of federal statutes that protect against discrimination in both public accommodations and employment, neither customers nor servers are likely to find redress under existing law for the forms of discrimination that are most likely to occur in tipped service

${ }^{318}$ Dirks \& Rice, Dining While Black, supra note 107, at 271.

${ }^{319}$ Ayres et al., supra note 19, at 1650-51; see also Brewster \& Mallinson, supra note 113, at 1064 (describing a similar cycle in restaurants).

${ }^{320}$ Dirks \& Rice, Tipping as Social Artifact, supra note 29, at 33-34.

321 See discussion supra Part IV.A.

${ }^{322}$ Bayard de Volo, supra note 14 , at 362. 
transactions. Customers of color who receive inferior service might well be deprived of their statutorily protected right to "the full and equal enjoyment" of places of accommodation without discrimination on the ground of race, color, religion, or national origin, ${ }^{323}$ but such claims are difficult to establish. ${ }^{324}$ Although some blatantly discriminatory treatment of customers has resulted in litigation, ${ }^{325}$ the ways in which service varies based on stereotypes of customers' tipping practices are generally quite ambiguous. ${ }^{326}$ "Service with a smirk" is a classic example of the subtle, perhaps unconscious, discrimination that both is difficult to prove and might not be worth litigating in individual cases, ${ }^{327}$ despite the cumulative cost to a customer of her regular encounters with "everyday racism." 328

One might think that servers would have better prospects for legal remedy under employment discrimination law when they receive lower compensation than their coworkers for providing the same level of service. Again, however, existing laws do not reach the problem of discrimination in tipping. First, and perhaps obviously, employment discrimination law provides no remedy against customers because they are not the server's "employer," 329 despite their performance of the employer-like tasks of monitoring and compensating the server's performance. Second, tips are voluntary, so the customer has no legal obligation to pay any gratuity. ${ }^{330}$

32342 U.S.C. $\$ 2000$ a (2006) ("Prohibition against discrimination or segregation in places of public accommodation"). Note that the statute does not prohibit discrimination because of gender. $I d$.

${ }^{324}$ See, e.g., Regina Austin, "Bad for Business": Contextual Analysis, Race Discrimination, and Fast Food, 34 J. MARShall L. REv. 207, 230-42 (2000); Deseriee A. Kennedy, Consumer Discrimination: The Limitations of Federal Civil Rights Protection, 66 Mo. L. REv. 275 (2001).

325 See supra notes 247-48.

${ }^{326}$ See discussion supra Part IV.B.

${ }^{327}$ See Siegelman, supra note 28 , at 85 (discussing the likelihood that "potential plaintiffs realize that a large fraction of the perceived incidents of discrimination they experience are in some sense not worth the costs of taking to court" on a "cost/benefit calculation"; noting, however, that "[t]his is not to suggest that such incidents are psychologically unimportant . ...").

328 See Kennedy, supra note 324, at 294-302.

${ }^{329}$ See 42 U.S.C. $\$ 2000 \mathrm{e}$ (b) (2006) (defining “employer").

${ }^{330}$ See supra Parts II and III. In addition, existing civil rights laws focus on protecting buyers, not sellers, against discrimination, despite the "civil rights concerns" that "consumer discretion in retail transactions" might raise. Ayres et al., supra note 19 , at 1656,1663 . Ayres and his colleagues also note the "abundant logistical problems" in using civil rights statutes to discourage discrimination on the customer's side, including " $[\mathrm{t}]$ he difficulty and cost of proving that an individual passenger tipped less because of the driver's race ... .Id. at 1656. 
Existing models of employment discrimination law also fail to hold the actual employer liable for unequal compensation based on tips. Title VII of the Civil Rights Act of 1964 prohibits discrimination in employment, but neither of the two prevailing models for establishing liability under Title VII is suited to address the kind of discrimination that an employer's decision to base employee compensation on tips tends to produce. These models, disparate treatment and disparate impact, have been called the "defective dichotomy,"331 and their failure to reach unequal compensation based on tips offers support for that label.

First, the disparate treatment model imposes liability only if the employer intentionally discriminates on a prohibited basis. ${ }^{332}$ Compensating servers through tips is a facially neutral practice, however, and it is unlikely that employers choose that basis for compensation "because of" the servers' race or gender. ${ }^{333}$

Disparate impact liability, on the other hand, does not require that the employer intend to discriminate and can apply to facially neutral practices, but it too is not a good fit for discrimination in compensation based on tips. ${ }^{334}$ To present a prima facie case of disparate impact, the

${ }^{331}$ Deborah M. Weiss, A Grudging Defense of Wal-Mart v. Dukes, 24 YALE J.L. \& FEMINISM 119, 124 (2012).

${ }^{332}$ See, e.g., Int'l Bhd. of Teamsters v. United States, 431 U.S. 324, 335 n. 15 (1977) (stating that "[p]roof of discriminatory motive is critical" in a disparate treatment case); Reeves v. Sanderson Plumbing Prods., Inc., 530 U.S. 133, 135 (2000) (stating, in a case under the Age Discrimination in Employment Act, " $[t]$ he ultimate question in every employment discrimination case involving a claim of disparate treatment is whether the plaintiff was the victim of intentional discrimination.").

${ }^{333}$ For discussion of employers' incentives for basing compensation on tips, see discussion infra Part $V$. Even if an employer is aware of the potentially discriminatory effects of tipping on compensation, that awareness does not amount to discriminatory intent. See Pers. Adm'r v. Feeney, 442 U.S. 256, 279 (1979) (stating in an equal protection case that " [d] iscriminatory purpose" . . implies more than intent as volition or intent as awareness of consequences. It implies that the decisionmaker ... selected or reaffirmed a particular course of action at least in part 'because of,' not merely 'in spite of,' its adverse effects upon an identifiable group.") (footnotes omitted) (citation omitted) (internal punctuation omitted).

334 Aside from problems with doctrinal fit, the statistical showing needed to support a prima facie case of disparate impact would likely present a formidable obstacle. See generally MiCHAEL J. ZIMMER ET AL., CASES AND MATERIALS ON EMPLOYMENT DISCRIMINATION 236-38 (8th ed. 2013) (describing the quantitative showing required to prove that an employment practice causes a disparate impact). But see Lynn et al., Consumer Racial Discrimination in Tipping, supra note 25, at 1057; Michael Lynn \& Glenn Withiam, Tipping and Its Alternatives: Business Considerations and Directions for Research, $22 \mathrm{~J}$. SERVICES MARKETING 328, 333 (2008) (noting potential for disparate impact 
plaintiff must identify a "particular employment practice that causes a disparate impact on the basis of race, color, religion, sex, or national origin ...." ${ }^{335}$ It is doubtful whether an employer's decision to base compensation on tips-effectively allowing individual customers to determine how much to reward their particular servers-constitutes the kind of "affirmative act by the employer [that] must be shown in order to establish causation" in a disparate impact case. ${ }^{336}$ That courts would view a policy allowing customers to decide on tips as a "particular employment practice" seems especially questionable following the Supreme Court's recent statements in Wal-Mart Stores, Inc. v. Dukes, rejecting the plaintiffs' argument that the defendant's policy of "allowing discretion by local supervisors" constituted a uniform employment practice. ${ }^{337}$ The Court viewed that "policy" as "just the opposite of a uniform employment practice," stating that "it is a policy against having uniform employment practices." 338 Furthermore, in Wal-Mart, the local supervisors were employed by the defendant, whereas customers are outside parties not under the employer's control.

Although current civil rights laws fail to address either customer or server discrimination in tipped transactions, an alternative approach might reduce it. That approach would target the practice of tipping itself, by placing greater responsibility on employers to compensate their workers. Making tips less important should, in turn, decrease the ability and incentive for customers and servers to discriminate against one another. Theoretically, tipping could be banned outright, ${ }^{339}$ but a blanket prohibition would not be easily enforced. ${ }^{340}$ Instead, commentators have

liability under Title VII of the Civil Rights Act of 1964 and suggesting that, " $[t]$ o protect themselves against such a lawsuit, large chains should test to see if tipping has a disparate impact in their businesses and, if it does, should either pool tips or replace tipping with one of its alternatives.").

${ }^{335} 42$ U.S.C. $\$ 2000 \mathrm{e}-2(\mathrm{k})(1)(\mathrm{A})(\mathrm{i})(2006)$.

${ }^{336}$ EEOC v. Chi. Miniature Lamp Works, 947 F.2d 292, 305 (7th Cir. 1991) (rejecting a district court's view that employer's "passive reliance on employee word-of-mouth recruiting [w] as a particular employment practice for the purposes of disparate impact").

337131 S. Ct. 2541, 2554 (2011) (emphasis in original).

${ }^{338}$ Id. (emphasis in original). The effect of this decision on disparate impact doctrine is unclear, however, as the Court ostensibly was deciding an issue of class certification (i.e., whether the plaintiffs had established the "commonality" requirement of Federal Rule of Civil Procedure 23(a)(2)).

${ }^{339}$ Some states did enact anti-tipping statutes during the early twentieth century. See SEgRAVE, supra note 15, at 29.

${ }^{340}$ As Ayres and his colleagues have pointed out: "Who is to know if a passenger slips a driver a few extra dollars before exiting the cab? And why would police have an incentive to investigate or prosecute such small-potatoes infractions? Moreover, we imagine that the prohibition would incense many 
suggested other means to limit the effects of tipping. Ayres and his colleagues, for example, have offered a "tentative proposal" ${ }^{341}$ to reduce tipping by instituting a service compris regulation, similar to the system in other countries of imposing a service charge. ${ }^{342}$ They argue that this regulation would likely reduce discrimination in both directions, ${ }^{343}$ although its countervailing effects (increasing the overall cost of service and reducing workers' service incentives) might "militate against" their proposal. ${ }^{344}$ Another alternative would be to amend wage laws by reducing or eliminating the "tip credit" that allows employers to pay tipped employees less than the standard minimum wage. ${ }^{345}$

Proposals that aim to regulate tipping deserve attention and might reduce discrimination in service encounters. Beyond providing support for legal reforms related to tipping and wage laws, however, close examination of discrimination in tipped service encounters reveals the importance of an understanding of discrimination that focuses less on individual decision making and more on the role that organizations play in producing and promoting unequal treatment. Discrimination in tipping illuminates what Professor Tristin Green has called "structural discrimination": "a form of discrimination that involves the interplay between individuals and the larger organizational environments in which they work." ${ }^{346}$ In contrast to existing models of employment discrimination law, ${ }^{347}$ a structural approach "envisions an employer obligation to avoid facilitating or enabling discriminatory bias in

passengers ('What right does the government have to say that I can't tip?') and would incite noncompliance." Ayres et al., supra note 19, at 1658-59.

${ }^{341}$ Id. at 1656.

${ }^{342}$ In the context of taxicab rides, on which the study by Ayres and his colleagues focused, the proposed regulation would require metered prices to increase by $15 \%$ and cabs to prominently display "Tip Included" decals. Id. at 1659.

${ }^{343}$ Id. at $1658-61$.

${ }^{344}$ Id. at 1661-62 (noting that including the tip might "make taxis too expensive for poor people (who are themselves disproportionately people of color)" and "reduce cab drivers' incentives to provide high-quality service").

${ }^{345}$ As explained in note 6, supra, the Fair Labor Standards Act provides a "tip credit" (currently \$5.12) towards the minimum wage obligation for employers of tipped workers under which the employer may be required to pay a cash wage of as low as $\$ 2.13$ per hour. See 29 U.S.C. $\$ 203(\mathrm{~m})$ (2006); WAGE AND Hour Division, U.S. DEPT. OF LABOR, FACT SHEET \#15, supra note 6. Some states allow no tip credit or a smaller tip credit than the federal standard, thereby requiring employers to pay the full or closer to the standard minimum wage. See generally WAGE AND HOUR Division, U.S. DEPT. OF LABOR, MINIMUM WAGES FOR TIPPED EMPLOYEES, available at $\mathrm{http}: / / \mathrm{www} . \mathrm{dol} . \mathrm{gov} / \mathrm{whd} / \mathrm{state} / \mathrm{tipped.htm}$ (last visited on August 2, 2013).

${ }^{346}$ Green, supra note 34 , at 857.

${ }^{347}$ See supra notes 331-38 and accompanying text. 
workplace decisionmaking" ${ }^{348}$ and "seeks to minimize the operation of discriminatory bias by altering the workplace context in which day-today perceptions and judgments are made." ${ }^{349}$

Although tipped service transactions directly involve just the customer and server, they take place within an organizational framework that is created by the third member of the triangular relationship, the firm-that is, the owner of the business through which the customer purchases the service and the server is employed. That framework facilitates and enables discriminatory bias in the decisions of the direct parties. Moreover, that organizational framework also encourages the firm to make decisions and take actions that reinforce the discriminatory dynamics of the service encounter.

The firm's interests in tipping in some ways align with those of customer and server, but in other ways they are distinct. Like the customer, the firm wants its employees to deliver high quality service, because good service leads to satisfied customers and higher profits. ${ }^{350}$ Like the server, the firm wants customers to tip generously, because large tips help the firm recruit and retain employees. ${ }^{351}$ But the firm benefits from tipping in other ways, as well. In particular, when customers provide a large share of servers' compensation through tips, the firm can reduce not just its costs of compensation, ${ }^{352}$ but also its costs of management, because customers relieve the firm of the need to "closely monitor [servers] to ensure reasonably polite, prompt service." $" 353$

The firm also is the member of the triad whose decisions and actions have the broadest reach. While the server has some discretion to provide different levels and kinds of service to individual customers, the firm controls the larger business decisions that affect customers' access to the service itself. And while the customer may supplant the firm to some degree in managing the server's encounter-level behavior, the firm

${ }^{348}$ Green, supra note 34 , at 857.

${ }^{349} \mathrm{Id}$. at 860 (noting that a structural approach "shares common ground with recent efforts within the law and economics school to account for bounded rationality through law").

${ }^{350}$ See Erickson, supra note 120 , at 566.

${ }^{351}$ See, e.g., Lynn \& Withiam, supra note 334, at 332.

${ }^{352}$ See Azar, Business Strategy, supra note 3, at 519.

${ }^{353}$ Bayard de Volo, supra note 14, at 362 . Tipping does present disadvantages for firms, on the other hand, including that it removes the compensation decision from the employer; "creates role conflict" for employees, who "become agents of the customer as well as of the firm"; and, as we have seen, "motivates employees to discriminate against customers perceived to be poor tippers." Lynn et al., Voluntary Tipping and the Selective Attraction and Retention of Service Workers in the USA, supra note 48, at 1887-88. 
determines the work conditions and compensation structure under which the server labors day to day. These high level decisions of the firm have a broad impact on the economic opportunities available to servers and the services available to customers. Accordingly, it is important to recognize the effects of the practice of tipping on the firm's incentives to act in ways that may undermine the ability to achieve equality for patrons and servers alike. Even a brief look suggests several ways in which tipping provides firms with incentives to make decisions and justifications to take actions that have a disproportionately negative impact on women and people of color but often elude legal redress.

The firm's expectations about which customers are likely to tip more or less generously and which servers are likely to receive bigger or smaller tips can influence a range of decisions. First, the basic business decisions of which markets to enter and which to avoid-decisions that affect the availability of services to particular communities-can turn in part on restaurateurs' perceptions of the tipping habits of those communities. ${ }^{354}$ Restaurant executives take into account such factors as employee turnover in making location decisions, because turnover increases costs and lowers profit margins. ${ }^{355}$ One factor that affects turnover is servers' dislike of waiting on customers whom they perceive to be poor tippers. This "tipping-related turnover makes black communities relatively unattractive target markets for restaurants and restricts the expansion of restaurant chains into those markets." 356

Not only do such stereotype-driven business decisions limit black consumers' access to full-service and higher-end restaurants, but they also contribute to a self-reinforcing dynamic. That is, the less available such establishments are to people of color, the less frequently people of color will patronize restaurants where tipping is expected, and the less familiar they will be with the restaurant tipping norm-a factor that explains in part the tendency of African Americans to tip less than other groups. ${ }^{357}$

${ }^{354}$ See Lynn, Tipping Norms, supra note 218, at 15 (quoting Linda Wallace, The Restaurant Wars: Dare To Go Where No Broker Has Gone Before, DiversityInc.com, Aug. 9, 2001); see also Amer, supra note 219.

${ }^{355}$ Lynn, Tipping Norms, supra note 218, at 12, 14.

${ }^{356} I d$. at 15.

${ }^{357}$ See discussion supra Part IV.C. Furthermore, the lack of easy access to fullservice restaurants, combined with a history and expectation of discriminatory treatment in such settings, may account in part for black customers' preference for fast food restaurants, which are comparatively "inviting alternatives" because, among other features, they "seem to invite all kinds of patrons"; "[c]ustomers are waited on according to their place in line" so servers have less opportunity to "prefer one category of customer over another"; customers "wait on themselves" once they receive their food; and "[t]he absence of waiters or 
Of course, the firm's decisions affect the experience not just of customers, but also of servers. Here again, expectations about tipping can influence decisions and practices from hiring to working conditions. And while employment practices directly affect those whom the firm does (and does not) hire and how it treats its workers, they also contribute to a work environment that promotes discrimination against customers.

Two points are important to recognize in understanding how expectations about tipping affect the employment and work conditions of servers. First, and as already noted, high tips help firms to recruit and retain employees and reduce their own compensation and management costs. Second, tipped positions (such as waiter) are generally more highly compensated than non-tipped positions (such as cook or busboy) within a restaurant, both because of the tips themselves and because tipped employees "rarely report all their tip income" for tax purposes. ${ }^{358}$ At the same time, tip earnings can vary greatly from one type of establishment to the next, with wages and tips generally being greatest in high-price, more formal restaurants and smallest in medium- and lowprice restaurants..$^{359}$

Accordingly, firms have incentive to hire, and the more lucrative positions tend to go to, individuals who are likely to earn bigger tips. ${ }^{360}$

waitresses who work for tips minimizes conflicts over the quality of service." Austin, supra note 324 , at 227-28. This is not to say, however, that customers of color do not face discrimination in fast food restaurants, for they surely do, as Professor Austin discusses. Id. at 230-42.

358 See Lynn \& Withiam, supra note 334 , at 332 (also noting that "many tipped workers earn far more in tips than they could possibly earn in wages from other types of work involving similar skill sets"). Note, on the other hand, that some restaurants have "tip out" policies that "redistribute income from tipped employees to non-tipped employees." Id. One writer has argued in favor of a service charge over tipping in part because "tipping facilitates significant tax evasion." Yoram Margalioth, The Case Against Tipping, 9 U. PA. J. LAB. \& EMP. L. 117, 118-19 (2006) (also arguing, inter alia, that tipping facilitates prejudice, citing Ayres et al., supra note 19).

${ }^{359}$ In 1996, David Neumark reported the following regarding his study of restaurant servers' earnings:

Regardless of how we calculate average hourly earnings, the data indicate large positive earnings differentials in high-price restaurants relative to both medium- and low-price restaurants, .... For example, ... average hourly earnings in high-price restaurants $(\$ 18.57)$ are 47 percent higher than earnings in medium-price restaurants $(\$ 12.61)$, and 68 percent higher than earnings in low-price restaurants $(\$ 11.08)$.

Neumark, supra note 157, at 931-32.

${ }^{360}$ See generally Lynn et al., Voluntary Tipping and the Selective Attraction and Retention of Service Workers in the USA, supra note 48. 
To the extent that tips correlate with customer preferences-which, as we have seen, often align with social stereotypes-it is perhaps no surprise that "[t] $]$ he best jobs serving food still go to white men." ${ }^{361}$ To be sure, customer preferences with regard to race or gender provide no legal justification for discrimination under federal employment discrimination law. ${ }^{362}$ Nevertheless, customers' preferences do have an influence on restaurant hiring patterns. First, customer preferences can have a direct effect on the tip earnings of individual servers, which may act as a sort of screening device by which servers who are, or are likely to be, wellrewarded enter and stay employed in restaurant service and those who tend to receive low tips self-select out of server positions. ${ }^{363}$

Second, social stereotypes that align with customer preferences, both actual and perceived, can promote gender and racial stratification in restaurant work. ${ }^{364}$ The restaurant industry has a long history of both kinds of segregation that continues to the present. Even today, white male servers dominate in "elite or upscale dining establishments emulating an Old World or European model" 365 - a model that is exemplified by the defendant in the well-known Title VII case of Equal Employment Opportunity Commission v. Joe's Stone Crab, Inc. ${ }^{366}$ White

\footnotetext{
361 Austin, supra note 324 , at 223.

362 See, e.g., Diaz v. Pan Am. World Airways, Inc., 442 F.2d 385, 389 (5th Cir. 1971) (stating, in Title VII case, "[I]t would be totally anomalous if we were to allow the preferences and prejudices of the customers to determine whether the sex discrimination was valid. Indeed, it was, to a large extent, these very prejudices the Act was meant to overcome."); EEOC v. St. Anne's Hosp. of Chi., Inc., 664 F.2d 128, 133 (7th Cir. 1981) (rejecting customer preference justification based on race); Fernandez v. Wynn Oil Co., 653 F.2d 1273, 127677 (9th Cir. 1981) (rejecting customer preference justification based on sex).

${ }^{363}$ See Lynn \& Withiam, supra note 334, at 332; Lynn et al., Voluntary Tipping and the Selective Attraction and Retention of Service Workers in the USA, supra note 48 .

${ }^{364}$ For example, David Neumark found evidence that customer discrimination may be partially responsible for discrimination against women in restaurant hiring. We tend to think that this customer discrimination is not a direct preference of male clients for male waitpersons, but rather a preference of male clients for the types of restaurants that hire male wait staff, perhaps because such hiring signals "traditional" or "prestigious" restaurants.
}

Neumark, supra note 157 , at 936.

${ }^{365}$ Austin, supra note 324 , at 223.

${ }^{366} 220$ F.3d 1263 (11th Cir. 2000), remanded to 136 F. Supp. 2d 1311 (S.D. Fla. 2001) (finding intentional disparate treatment sex discrimination in hiring of food servers). As the defendant's own restaurant industry expert testified regarding "the 'male only' server tradition":

It has been an attitude and standard, it comes from Europe. In all of Europe you will find in all of the grade three restaurants 
women, in contrast, are more likely to serve at middle-range and lowerend, family-style restaurants. ${ }^{367}$ Black workers have not cracked the "glass ceiling" 368 either. ${ }^{369}$ Nor have they breached the wall that separates the dining room from the kitchen, for "front of the house" positions, including server, "tend[] to be filled by white Americans, while back of the house positions, especially those that [are] of lesser status and lower paying like dishwashers or 'busboys' [are] filled by people of color." ${ }^{370}$

These gender- and race-stratified staffing patterns not only match but also reinforce social stereotypes. These include stereotypes that equate (white) men with the more "dignified and reserved" work of "waitering" and women with the more "casual, familial form of interaction" that defines "waitressing," "371 and that value men for their competence and women for their looks. ${ }^{372}$ As discussed above, female servers may be motivated to conform to gender-based stereotypes through their demeanor and physical appearance in order to earn bigger tips, thereby

in Europe, there is an impression that service at that high level is the environment of men, and that it ought to be that way. ... Those [European] opinions and those sensibilities, I think were in fact carried here by restauranteurs who hoped to create something serious.... I don't think anybody thought about it. They said, well, men did it there. It tended to be men here, too, who had those skill sets, and so men were [sic] automatically became the labor pool.

220 F.3d at 1270 (quoting testimony of Karen McNeil).

${ }^{367}$ David Neumark examined the sex-based, "vertical segregation" in the restaurant industry and found "strong evidence of discrimination against women in high-priced restaurants, and weaker evidence of discrimination in women's favor in low-price restaurants." Neumark, supra note 157, at 917-18. Among Neumark's findings were "a sizable sex gap in wages," with a "ratio of mean weekly earnings of waitresses to mean weekly earnings of waiters [of] 0.71 , and [a] ratio of median weekly earnings [of] 0.75 ," id. at 915 , and a strong preference among high-price restaurants for hiring male servers over "comparably matched" females, with males receiving interviews in $61 \%$ of the cases compared to females at $26 \%$, and males receiving job offers in $48 \%$ of the cases compared to females at $9 \%$. Id . at 925 .

${ }^{368}$ Christine Jolls, Is There a Glass Ceiling?, 25 HARV. WOMEN's L.J. 1 (2002) (examining the restaurant service market, among others).

${ }^{369}$ See Austin, supra note 324, at 224 (stating, with regard to restaurant service work, "Minorities are at the end of the line.").

370 Dirks \& Rice, Dining While Black, supra note 107, at 263. Dirks and Rice also note that, in the restaurants they studied, "white American males filled the management and owner positions ... with very few people of color or women working in such positions." Id. at 265.

${ }^{371}$ Hall, supra note 194, at 330; see also discussion supra Part IV.A.

372 See Lynn \& Simons, supra note 26, at 246-47, 250. 
providing one avenue for stereotype confirmation and entrenchment. ${ }^{373}$ Employers, too, may play into gender stereotypes to increase customer satisfaction and servers' tips, through such practices as dress and grooming codes that impose different standards on men and women ${ }^{374}$ but are difficult to challenge as sex discrimination in employment under existing standards. ${ }^{375}$

Racial stereotypes about servers mirror those about customers, ${ }^{376}$ holding that black servers are "bad for business" because they have "bad attitudes" and will not provide customers with attention and friendly service. ${ }^{377}$ Racial segregation in restaurant hiring further cements both sets of stereotypes, because it promotes the "culture of white servers" in restaurants. The racial divide produces an environment in which white, front-of-the-house workers, such as servers, have "had very little opportunity to work side by side with people of color" and "primarily relate to each other in sharing the experience of dealing directly with customers and working for tips." 378 As we have seen, this culture contributes to white servers' bias against, and delivery of inferior service to, black customers. ${ }^{379}$ Racial segregation within restaurants also means that "black Americans are disproportionately employed in restaurant kitchens ... where they have less opportunity to learn tipping norms." 380 In turn, this lack of familiarity with tipping contributes to "race-based tipping variability," 381 which is itself one factor in the self-perpetuating cycle of racial stereotype confirmation.

${ }^{373}$ See discussion supra Part IV.A.

${ }^{374}$ See Bayard de Volo, supra note 14, at 365-68.

${ }^{375}$ One prominent example of such sex-differentiated standards is the "Personal Best" grooming and appearance program that was adopted by Harrah's for its Reno casino and challenged as sex discrimination in Jespersen $v$. Harrah's Operating Company, Inc., 444 F.3d 1104 (9th Cir. 2006) (affirming district court's partial grant of defendant's motion for summary judgment). Among the requirements for female bartenders such as the plaintiff was that they wear a "facial uniform (full makeup)" based on a "facial template" that had been created for each woman by "professional image consultants." Id. at 1114 (Pregerson, J., dissenting). For further discussion of gender-based dress and grooming codes under employment discrimination law, see Jennifer L. Levi, Some Modest Proposals for Challenging Established Dress Code Jurisprudence, 14 DUKE J. GENDER L. \& POL'Y 243 (2007); Jennifer C. Pizer, Facial Discrimination: Darlene Jespersen's Fight Against the Barbie-fication of Bartenders, 14 DUKE J. GENDER L. \& POL'Y 285 (2007).

${ }^{376}$ See discussion supra Part IV.B.

377 See Austin, supra note 324, at 221-24.

${ }^{378}$ Dirks \& Rice, Dining While Black, supra note 107, at 266.

${ }^{379}$ See discussion supra Part IV.B.

${ }^{380}$ Brewster \& Mallinson, supra note 113, at 1064 (citation omitted).

381 Id. 
The examples outlined above suggest just a few ways in which firms' reliance on tipping to compensate their workers creates an organizational environment that facilitates and enables discrimination by those workers, their customers, and the firm itself. The time is right to reexamine both the triangular relationship ${ }^{382}$ and legal conceptions of how discrimination operates.

\section{CONCLUSION}

This Article has pointed out the ways in which tipped transactions provide incentives and opportunities for race and gender discrimination through the decisions and actions of both the immediate parties and the firm that controls the conditions under which customer and server interact. My hope is that the Article will contribute to legal and structural measures to address these issues and, more broadly, will add to our understanding of the influence and material consequences of social stereotypes and bias in everyday life.

382 This moment coincides with the call of researchers in other disciplines for further study of the implications of tipping for business and management strategy, in part because of the risks that it creates for discrimination in both service and employment. See, e.g., Azar, Business Strategy, supra note 3; Lynn \& Withiam, supra note 334; Lynn et al., Voluntary Tipping and the Selective Attraction and Retention of Service Workers in the USA, supra note 48. For one restaurateur's account of his experience with a "no tipping" policy and the benefits of that policy from a business perspective, see Jay Porter, Observations From A Tipless Restaurant, Part I: Overview (July 25, 2013), http://jayporter.co $\mathrm{m}$ /dispatches/observations-from-a-tipless-restaurant-part-1-overview/ (last visited Aug. 21, 2013) (introducing a five-part series). 